\title{
International Meteor Organization
}

\section{Meteor Shower Calendar}

\author{
compiled by Jürgen Rendtel ${ }^{1}$
}

\section{Introduction}

Welcome to the twenty-sixth International Meteor Organization (IMO) Meteor Shower Calendar, for 2016. Alastair McBeath edited all the previous 25 issues of this successful IMO booklet - an enormous achievement for which we are greatly indebted. Naturally, we intend to continue this publication and hope you continue to find it useful to plan your meteor observing activities.

The moonlight circumstances for optical observations of the three strongest annual shower peaks are mixed, with a waning crescent Moon for the Quadrantids, a gibbous waxing Moon for the possibly more active Perseids and full Moon for the Geminids. Full Moon also affects the Lyrids and considerable moonlight interference occurs close to the maxima of the Orionids and the Leonids. Much better conditions are found for the $\eta$-Aquariids, the Southern $\delta$-Aquariids, and for the Ursids.

Only a few showers are expected to show slight differences from the average this year. Since there is always a possibility of completely unexpected events, ideally meteor observing should be performed throughout the year. While often there are many observers active during periods of high or medium activity, one should keep in mind that new events may happen at other times too. Continuous monitoring is possible with automated video systems and by radio/radar systems, but is also worthwhile for visual observers during Moon-free nights. This way we can confirm the established sources, including the outer ranges of the known showers. We do appreciate that such regular observations may be impractical for many people however, so the Shower Calendar helps to highlight times when a particular effort might be most usefully employed. It indicates as well specific projects which need good coverage and attention.

The heart of the Calendar is the Working List of Visual Meteor Showers (Table 5) which has been updated so that it remains the single most accurate listing available anywhere today for naked-eye meteor observing. Nevertheless, it is a Working List which is continually subject to further modifications, based on the best data we had at the time the Calendar was written. Observers should always check for later changes noted in the IMO's journal WGN or on the IMO website. Vice versa, we are always interested to receive information whenwever you find any anomalies! To allow for better correlation with other meteor shower data sources, we give

\footnotetext{
${ }^{1}$ Based on information in the Meteor Observers Workbook 2014, edited by Jürgen Rendtel, IMO, 2014 (referred to as 'WB' in the Calendar), and "A Comprehensive List of Meteor Showers Obtained from 10 Years of Observations with the IMO Video Meteor Network" by Sirko Molau and Jürgen Rendtel (WGN 37:4, 2009, pp. 98-121; referred to as 'VID' in the Calendar), as amended by subsequent discussions and additional material extracted from reliable data analyses produced since. Results of model calculations of Mikhail Maslov and Jérémie Vaubaillon have been consulted. Particular thanks are due to David Asher, Esko Lyytinen, Robert Lunsford and Jérémie Vaubaillon for new information and comments in respect of events in 2016. Last but not least thanks to Alastair McBeath and Robert Lunsford for carefully checking the contents.
} 
the complete shower designation including the numbers taken from IAU's Meteor Data Center listings.

Video meteor observations allow us to detect sources of low meteor activity sources. The increasing number of radiants allows the identification between meteoroid streams with their parent objects, but also demonstrates that there are numerous sources which may produce single events, not only the annual recurring showers. Several such examples have been detected and analysed recently. Prominent examples are the September $\varepsilon$-Perseids $(2009,2013)$ and the $\kappa$-Cygnids (2014). From stream modelling calculations we know that one meteoroid stream may cause several meteor showers, and that a stream may be related to more than one parent object.

Observing techniques which allow to collect useful shower data include visual, video and stillimaging along with radar and radio forward scatter methods. Visual and video data allow rate and flux density calculations as well as determination of the particle size distribution in terms of the population index $r$ or the mass index $s$. Multi-station observing with still or video cameras can allow orbital data to be established, essential for meteoroid-stream investigations. Showers with radiants too near the Sun for observing by the various optical methods can be detected by forward-scatter radio or back-scatter radar observations - although attempts with optical observations can be useful too. Some of the showers are listed in Table 7, the Working List of Daytime Meteor Streams. Automated radio and radar work also allows 24-hour coverage of meteor activity.

The IMO's aims are to encourage, collect, analyze, and publish combined meteor data obtained from sites all over the globe, to improve our understanding of the meteor activity detectable from the Earth's surface. For best effects, all meteor workers, wherever you are and whatever methods you use to record meteors, should follow the standard IMO observing guidelines when compiling your information, and submit those data promptly to the appropriate Commission for analysis (contact details are at the end of the Calendar). Many analyses try to combine data obtained by more than one method, extending the ranges and coverage but also to calibrate results from different techniques. Thanks to the efforts of the many IMO observers worldwide since 1988 that have done this, we have been able to achieve as much as we have to date, including keeping the shower listings vibrant. This is not a matter for complacency however, since it is solely by the continued support of many people across the planet that our attempts to construct a better and more complete picture of the near-Earth meteoroid flux can proceed.

Although timing predictions are included below on all the more active night-time and daytime shower maxima, as reliably as possible, it is essential to understand that in many cases, such maxima are not known more precisely than to the nearest degree of solar longitude. In addition, variations in individual showers from year to year mean past returns are only a guide as to when even major shower peaks can be expected. As noted already, the information given here may be updated and added-to after the Calendar has been published. Some showers are known to show particle mass-sorting within their meteoroid streams, so the radar, radio, still-imaging, video and visual meteor maxima may occur at different times from one another, and not necessarily just in those showers. The majority of data available are for visual shower maxima, so this must be borne in mind when employing other observing techniques.

However and whenever you are able to observe, we wish you all a most successful year's work and very much look forward to receiving your data, whose input is possible via the online form on the IMO's website www.imo.net. Clear skies! 


\section{Antihelion Source}

The Antihelion Source (ANT) is a large, roughly oval area around $\alpha=30^{\circ}$ by $\delta=15^{\circ}$ in size, centred about $12^{\circ}$ east of the solar opposition point on the ecliptic, hence its name. It is not a true shower at all (hence it has no IAU shower number), but is rather a region of sky in which a number of variably, if weakly, active minor showers have their radiants. Until 2006, attempts were made to define specific showers within this complex, but this often proved very difficult for visual observers to achieve. IMO video results have shown why, because even instrumentally, it was impossible to define distinct and constantly observable radiants for many of the showers here! Thus we recommend for observers simply to identify meteors from these streams as coming from the ANT alone. Apart from this, we retained the July-August $\alpha$-Capricornids, and particularly the Southern $\delta$-Aquariids as visually separate and distinguishable showers from the ANT. Later in the year, the strength of the Taurid showers means the ANT should be considered inactive while the stronger Taurids are underway, from early September to early December. To assist observers, a set of charts showing the location for the ANT and any other nearby shower radiants is included here, to complement the numerical positions of Table 6, while comments on the ANT's location and likely activity are given in the quarterly summary notes.

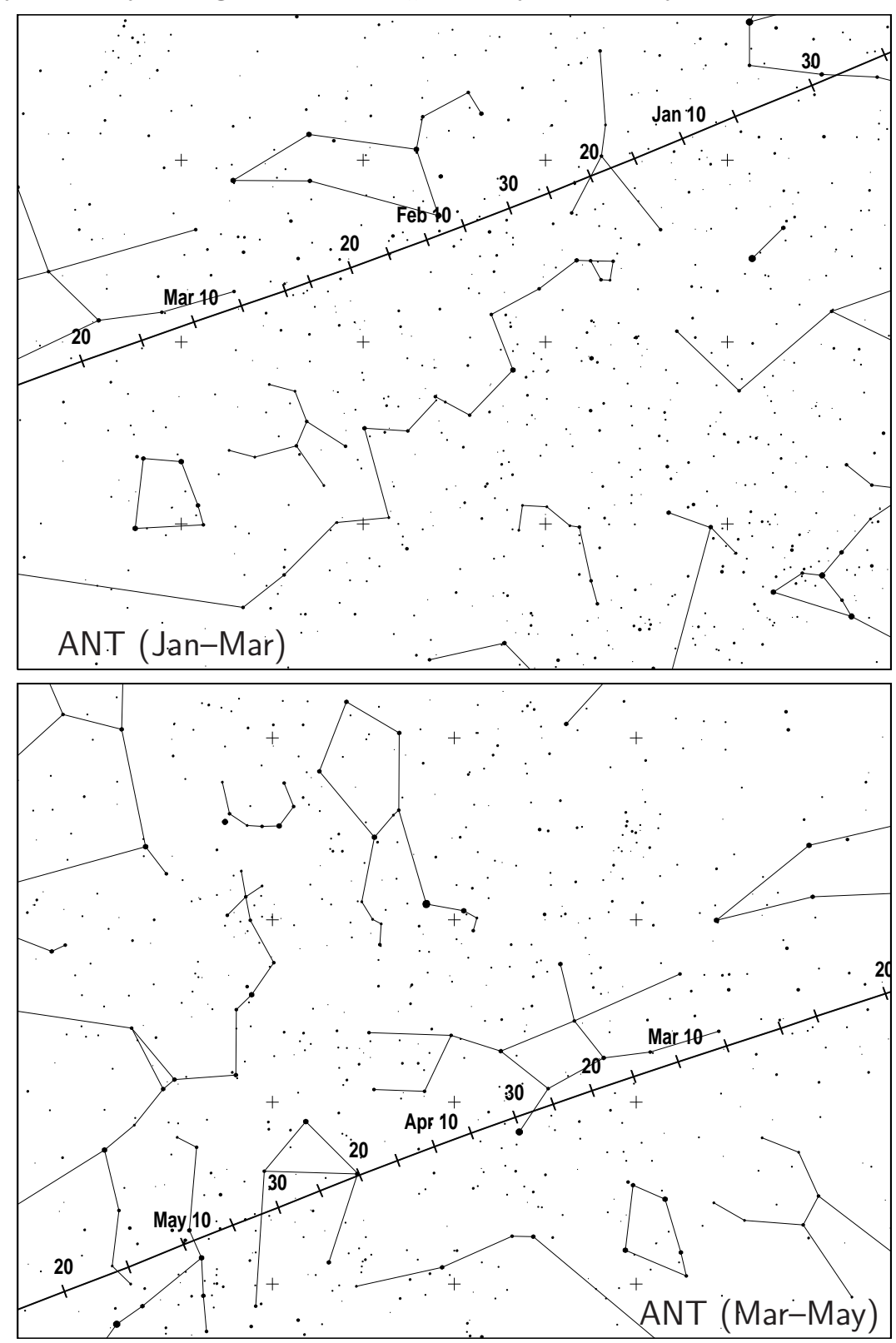




\section{January to March}

The year starts with the Quadrantid (010 QUA) peak for the northern hemisphere observers which is only partly affected by a waning moon in the morning hours. The maximum of the southern hemisphere's $\alpha$-Centaurids (102 ACE) coincides with the new Moon. The possible minor $\gamma$-Normids (118 GNO) of March have a first-quarter Moon. The ANT's radiant centre starts January in south-east Gemini, and crosses Cancer during much of the month, before passing into southern Leo for most of February. It then glides through southern Virgo during March. Probable ANT ZHRs will be $<2$, although IMO analyses have suggested there may be an ill-defined minor peak with ZHRs $\approx 2$ to 3 around $\lambda_{\odot} \approx 286^{\circ}-293^{\circ}$ (2016 January 6 to 13), and ZHRs could be $\approx 3$ for most of March. From theoretical modelling Mikhail Maslov indicates that there might be a weak activity of faint, very slow meteors $(15.5 \mathrm{~km} / \mathrm{s})$ on March 28-30 from a radiant near $\mu$ Leporis $\left(\alpha=78^{\circ}, \delta=-16^{\circ}\right)$. The meteoroids are from comet 252P/LINEAR and were ejected in 1915, 1921 and 1926. The ZHR may just be 5-10 and would be visible from tropical and southern locations in the evening. The most probable period is March $28,11^{\mathrm{h}}-18^{\mathrm{h}}$ UT, so central African longitudes east to east Asia and Oceania would be best placed.

Timings (rounded to the nearest hour) for the daytime shower maxima this quarter are: Capricornids/Sagittariids (115 DCS) - February 2, $04^{\mathrm{h}}$ UT and $\chi$-Capricornids (114 DXC) February 14, $05^{\mathrm{h}}$ UT. Recent radio results have implied the DCS maximum may fall variably sometime between February 1-4 however, while activity near the expected DXC peak has tended to be slight and up to a day late. Both showers have radiants $<10^{\circ}-15^{\circ}$ west of the Sun at maximum, so cannot be regarded as visual targets even from the southern hemisphere.

Quadrantids (010 QUA)

Active: December 28-January 12; Maximum: January 4, $08^{\mathrm{h}} 00^{\mathrm{m}} \mathrm{UT}\left(\lambda_{\odot}=283^{\circ} .16\right)$,

but perhaps earlier - see text;

$\mathrm{ZHR}=120$ (can vary $\approx 60-200) ;$

Radiant: $\alpha=230^{\circ}, \delta=+49^{\circ}$; Radiant drift: see Table 6 ;

$V_{\infty}=41 \mathrm{~km} / \mathrm{s} ; r=2.1$ at maximum, but variable.

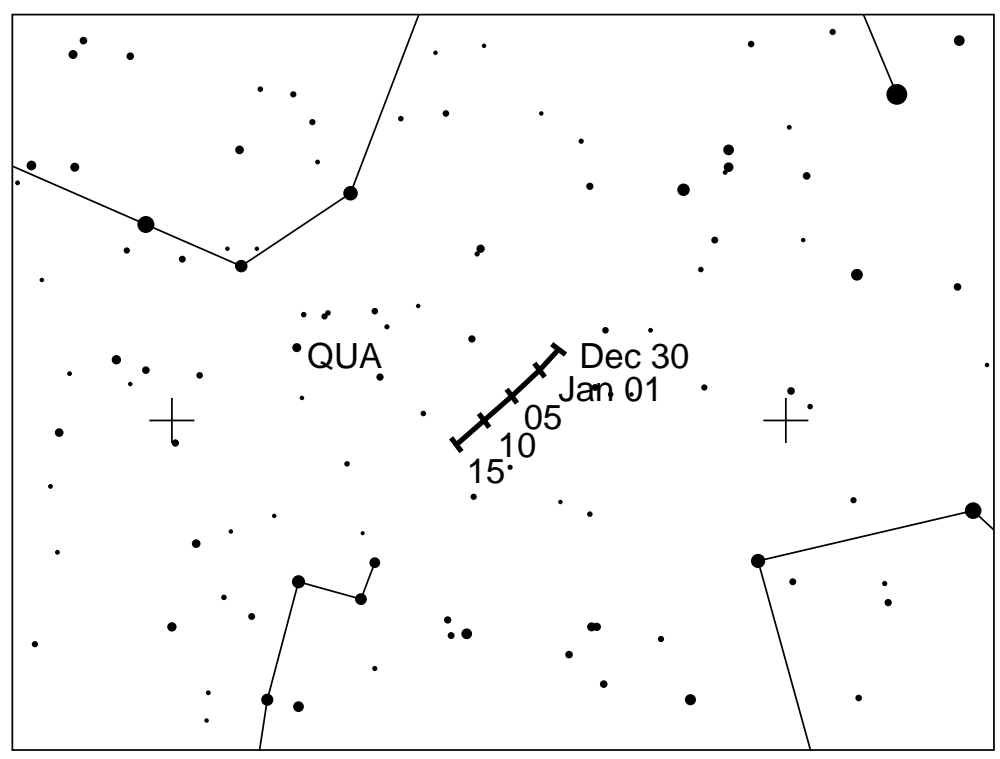

A last quarter Moon on January 2 creates favourable viewing conditions for the predicted Quadrantid maximum on January 4. For many northern hemisphere sites, the shower's radiant is 
circumpolar, in northern Boötes, from where it first attains a useful elevation after local midnight, steadily improving through till dawn. The $08^{\mathrm{h}} \mathrm{UT}$ timing for the peak will be too late even in the extreme west of mainland Europe while North American observers are in a better position. The $\lambda_{\odot}=283^{\circ} .16$ maximum timing is based on the best-observed return of the shower ever analysed, from IMO data collected in 1992, as confirmed by radio results in most years since 1996. Typically, the peak is normally short-lived, so can be easily missed in just a few hours of poor northern-winter weather, which may be why the ZHR level apparently fluctuates from year to year. Model calculations of Vaubaillon provide indications that the peak may occur earlier and may show a maximum between January $3,22^{\mathrm{h}}$, and January $4,2^{\mathrm{h}} \mathrm{UT}$. This timing would be optimal for European longitudes. An added level of complexity comes from the fact mass-sorting of particles across the meteoroid stream related to the comet $96 \mathrm{P} / \mathrm{Machholz}$ and the minor planet $2003 \mathrm{EH}_{1}$ may make fainter objects (radio and telescopic meteors) reach maximum up to 14 hours before the brighter (visual and photographic) ones, so observers should be alert throughout the shower. A few years this century seem to have produced a, primarily radio, maximum following the main visual one by some 9-12 hours too. Visual confirmation of any repeat of such behaviour would be welcomed. QUA activity tends to be very low more than a day or so from the peak, and past observations have suggested the radiant is diffuse away from the maximum too (perhaps because of this lower activity then), contracting notably during the peak itself. Imaging observations would be welcomed to help investigate this topic. The New Moon on January 10 leaves also room to collect data of the outer range of the shower which is not yet well studied.

\section{$\alpha$-Centaurids (102 ACE)}

Active: January 28-February 21; Maximum: February 8, $18^{\mathrm{h}} 30^{\mathrm{m}} \mathrm{UT}\left(\lambda_{\odot}=319.2\right)$;

$\mathrm{ZHR}=$ variable, usually $\approx 6$, but may reach $25+$;

Radiant: $\alpha=210^{\circ}, \delta=-59^{\circ}$; Radiant drift: see Table 6;

$V_{\infty}=56 \mathrm{~km} / \mathrm{s} ; r=2.0$.

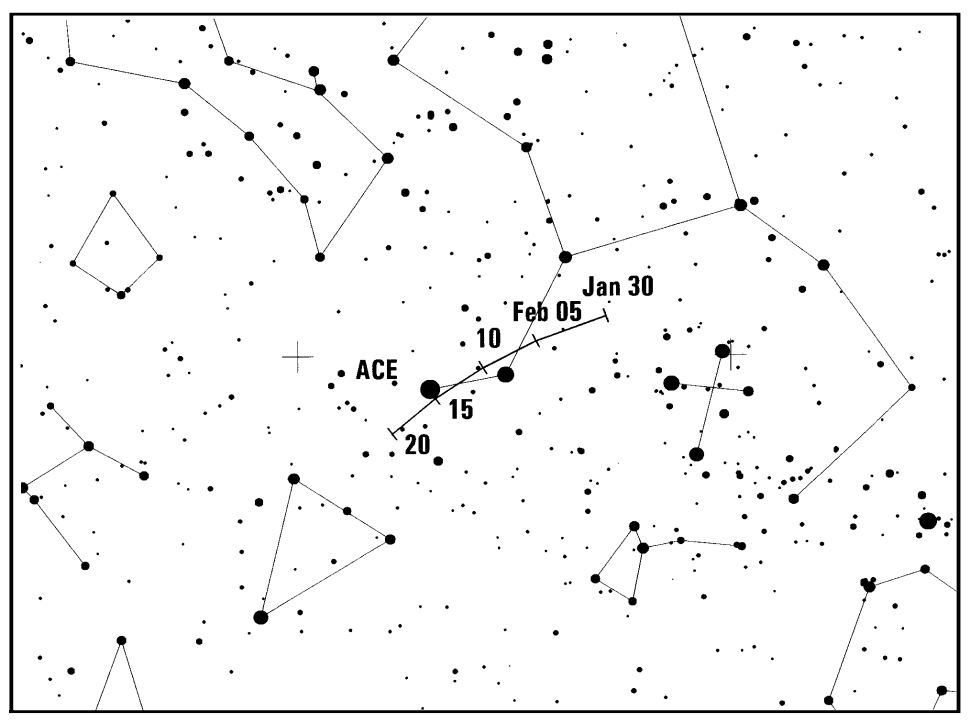

In theory, the $\alpha$-Centaurids are one of the main southern summer high points, from past records supposedly producing many very bright, even fireball-class, objects (meteors of at least magnitude -3$)$, commonly with persistent trains. The average peak ZHR between 1988-2007 was merely 6 though (WB, p. 18), albeit coverage has frequently been extremely patchy. Despite this, in 1974 and 1980, bursts of only a few hours' duration apparently yielded ZHRs closer to 20-30. As with many southern hemisphere sources, we have more questions than answers at 
present, nor can we be sure when, or if, another stronger event might happen. Based on the assumption that the shower is of a long orbital period type, there was a possibility calculated for a fresh outburst on 2015 February 8, of which we have no observational confirmation. Instead, there is a report of an airborne activity observation on February 14. The shower's radiant is nearly circumpolar for much of the sub-equatorial inhabited Earth, and is at a useful elevation from late evening onwards. With the New Moon on February 8 there are perfect conditions to collect data around the maximum period.

\section{$\gamma$-Normids (118 GNO)}

Active: February 25-March 28; Maximum: March $14\left(\lambda_{\odot}=354^{\circ}\right) ; \mathrm{ZHR}=6$;

Radiant: $\alpha=239^{\circ}, \delta=-50^{\circ}$, Radiant drift: see Table 6 ;

$V_{\infty}=56 \mathrm{~km} / \mathrm{s} ; r=2.4$.

For most of their activity, $\gamma$-Normid ZHRs seem to be virtually undetectable above the background sporadic rate. An analysis of IMO data from 1988-2007 showed an average peak ZHR of $\approx 6$ at $\lambda_{\odot}=354^{\circ}$, with ZHRs $<3$ on all other dates during the shower (WB, p. 19). Results since 1999 have suggested the possibility of a short-lived peak between $\lambda_{\odot} \approx 347^{\circ}-357^{\circ}$, equivalent to 2016 March 7-17. Recent video and visual plotting information confirmed activity from that region, but a new analysis of video data obtained only from locations south of the equator has indicated that the activity occurs preferentially around March $25\left(\lambda_{\odot}=4^{\circ}\right)$ instead, from a radiant at $\alpha=246^{\circ}, \delta=-51^{\circ}$. Post-midnight watching yields better results, when the radiant is rising to a reasonable elevation from southern hemisphere sites (the radiant does not rise for many northern ones). The shower badly needs attention. March's First Quarter Moon on the 15th favours mainly the above documented first date on March 15. All observing techniques can be employed.

\section{April to June}

Meteor activity increases towards the April-May boundary, particularly caused by optically unobservable showers. Full Moon on April 22 completely ruins the Lyrid (006 LYR) maximum at 32.32 which falls on April 22 around $6^{\mathrm{h}}$ UT. The Moon also leaves only very little time during the evening for the $\pi$-Puppid (137 PPU) maximum on April 23. In 2016, both the $\boldsymbol{\eta}$-Aquariid (031 ETA) maximum period, due around May 5, and the $\boldsymbol{\eta}$-Lyrids (145 ELY) with a potential peak on May 9 or slightly later can be perfectly observed in moonless nights.

Daytime showers: In the second half of May and throughout June, most of the annual meteor action switches to the daylight sky, with six shower peaks expected during this time. Occasional meteors from the Arietids have been claimed as seen from tropical and southern hemisphere sites visually in past years. Although it is not possible to calculate ZHRs and activity profiles from such observations, all available data should be collected and reported to combine observations obtained with different techniques for calibration and completeness. For radio observers, the theoretical UT peak times for these showers are as follows:

April Piscids (144 APS) - April 20, 04

$\varepsilon$-Arietids (154 DEA) - May 9, $03^{\mathrm{h}}$;

May Arietids (294 DMA) - May 16, 04 ${ }^{\mathrm{h}}$;

o-Cetids (293 DCE) - May 20, 03 ${ }^{\text {h }}$;

Arietids (171 ARI) - June 7, $04^{\mathrm{h}}$ (more details see below);

$\zeta$-Perseids (172 ZPE) - June 9, 06 ${ }^{\mathrm{h}}$;

$\beta$-Taurids (173 BTA) - June 28, $05^{\mathrm{h}}$. 
Signs of most were found in radio data from 1994-2008, though some are difficult to define individually because of their proximity to other radiants. The maxima of the Arietids and $\zeta$ Perseids tend to blend into one another, producing a strong radio signature for several days in early to mid June. The shower maxima dates are not well established and may occur up to a day later than indicated above. There seems to be a modest recurring peak around April 24 as well, perhaps due to combined rates from the first two showers listed here, and possibly the $\delta$-Piscids, which we previously listed for many years as having a peak on April 24, although the IAU seems not to recognise this currently as a genuine shower. Similarly, there are problems in identifying the $o$-Cetids in the IAU stream lists, despite the fact this (possibly periodic) source was detected by radar more strongly that the $\eta$-Aquariids of early May when it was first observed in 1950-51. The current number and abbreviation given here for it is actually for the IAU source called the "Daytime $\omega$-Cetid Complex", because that seems a closer match to the $o$-Cetids as defined by earlier reports.

Theoretical modelling by Mikhail Maslov indicates that meteoroids released from comet P/2009 $\mathrm{WX}_{51}$ (Catalina) at rather high speeds (and hence should be very small) may cause activity on April 21 at $02^{\mathrm{h}} 02^{\mathrm{m}}$ UT. Further, the radiant at $\alpha=38^{\circ}, \delta=35^{\circ}$ close to the star 14 Tri is only $24^{\circ}$ west of the Sun. Any activity can only be observed by means of radio or radar.

The ANT should be relatively strong, with ZHRs of 3 to 4 through till mid April, and again around late April to early May, late May to early June, and late June to early July. At other times, its ZHR seems to be below $\approx 2$ to 3 . The radiant area drifts from south-east Virgo through Libra in April, then across the northern part of Scorpius to southern Ophiuchus in May, and on into Sagittarius for much of June.

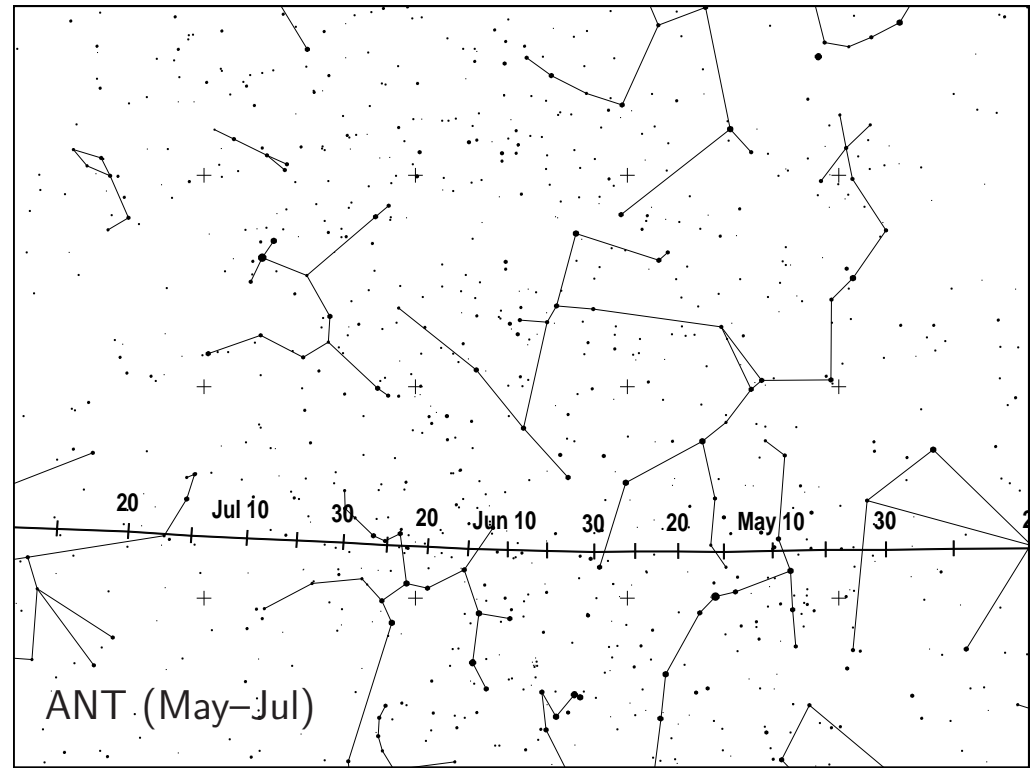

$\eta$-Aquariids (031 ETA)

Active: April 19-May 28; Maximum: May 5, 20 $\mathrm{hT}\left(\lambda_{\odot}=45.5\right)$;

$\mathrm{ZHR}=40$ (periodically variable, $\approx 40-85$ );

Radiant: $\alpha=338^{\circ}, \delta=-1^{\circ}$; Radiant drift: see Table 6 ;

$V_{\infty}=66 \mathrm{~km} / \mathrm{s} ; r=2.4$.

This stream is associated with Comet 1P/Halley, like the Orionids of October. Shower meteors are only visible for a few hours before dawn essentially from tropical and southern hemisphere sites. Some useful results have come even from places around $40^{\circ} \mathrm{N}$ latitude at times however, 
and occasional meteors have been reported from further north. The shower is one of the best for southern observers and would benefit from increased observer activity generally. The fast and often bright meteors make the wait for radiant-rise worthwhile, and many events leave glowing persistent trains. While the radiant is still low, $\eta$-Aquariids tend to have very long paths, which can mean observers underestimate the angular speeds of the meteors, so extra care is needed when making such reports.

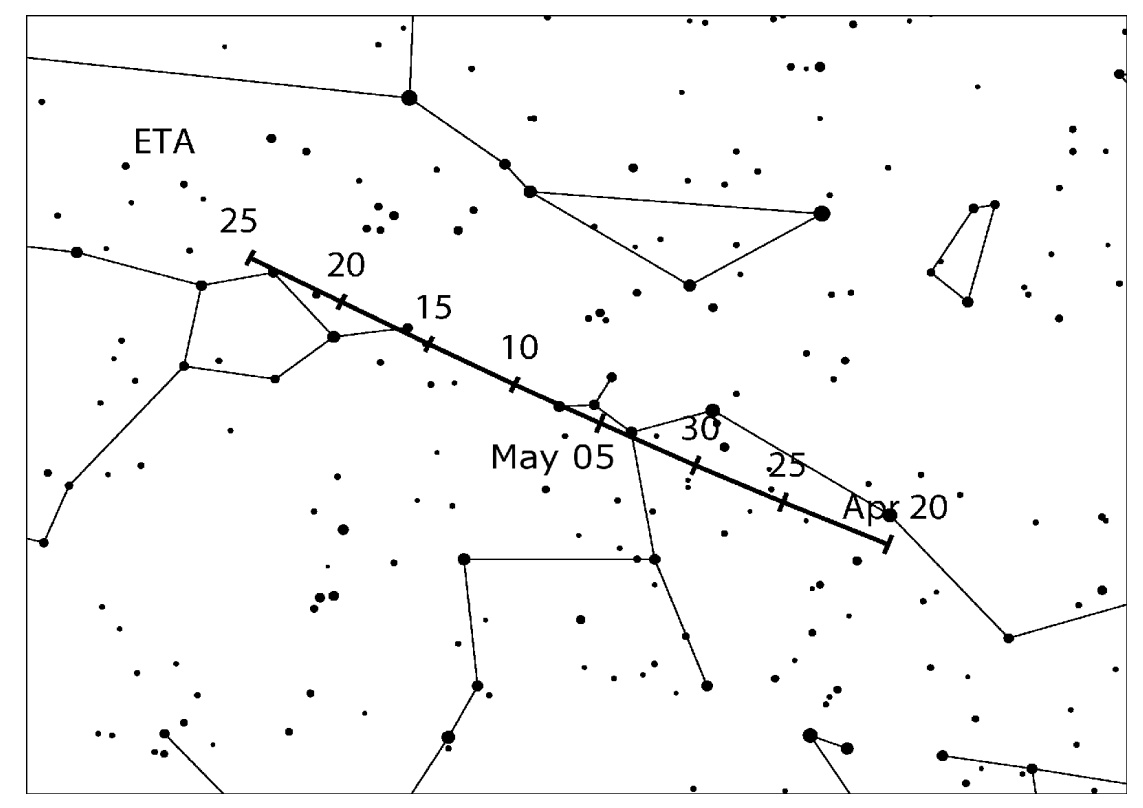

A relatively broad maximum, sometimes with a variable number of submaxima, occurs around May 5. IMO analyses based on data collected between 1984-2001, have shown that ZHRs are generally above 30 in the period May $3-10$. The peak rates appear to be variable on a roughly 12-year timescale. Assuming this Jupiter-influenced cycle is real, the next trough is due around 2014-2016, so ZHRs should be close to their relative poorest this year. Activity around the most recent ZHR peak period in circa 2008 and 2009 seemed to have been $\approx 85$ and 65 respectively. In 2013, ZHRs up to $\approx 70$ have been recorded (WB, p. 24). New Moon on May 6 creates ideal viewing conditions for whatever the shower provides this year. All forms of observing can be used to study it, with radio work allowing activity to be followed even from many northern latitude sites throughout the daylight morning hours. The radiant culminates at about $08^{\mathrm{h}}$ local time.

$\eta$-Lyrids (145 ELY)

Active: May $3-14 ;$ Maximum: May $8\left(\lambda_{\odot}=48\right.$.4); ZHR $=3$;

Radiant: $\alpha=287^{\circ}, \delta=+44^{\circ}$; Radiant drift: see Table 6 ;

$V_{\infty}=43 \mathrm{~km} / \mathrm{s} ; r=3.0$.

This weak shower is associated with Comet C/1983 H1 IRAS-Araki-Alcock. Most of the recent observational data on it has come from video results, which have suggested the maximum might fall at $\lambda_{\odot}=50^{\circ}$ instead (if so, on 2016 May 10). There is little evidence from visual observations as yet, but the discussion on p. 25 of WB has more information. Video as well as careful visual plotting will be needed to separate any potential $\eta$-Lyrids from the sporadics. The general radiant area is usefully on-view all night from the northern hemisphere (primarily), with essentially no Moon interference around May 8-10 this year. 
Daytime Arietids (171 ARI)

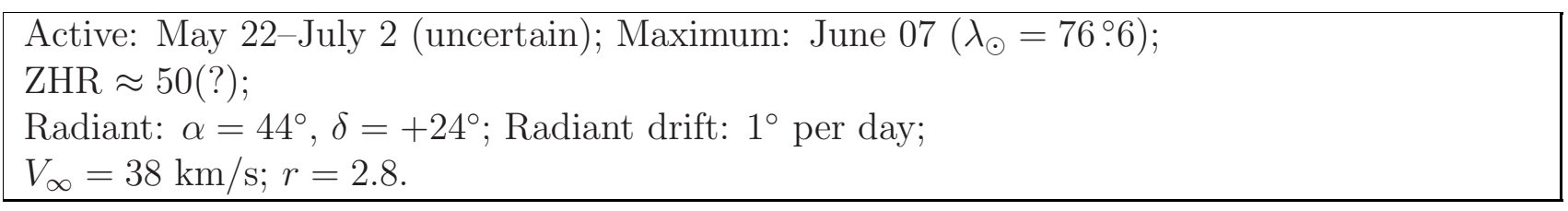

The radiant is located only about $30^{\circ}$ west of the Sun, but despite that, a few optical observations have been repeatedly reported from it in the past. However, its low radiant elevation by the time morning twilight is too bright means the number of shower meteors recorded by individual video or visual observers is always low. Consequently, an ongoing IMO project to pool data on the shower using all techniques was initiated in 2014, to combine results from many independent observing intervals, even those periods which contain few, or even no ARI meteors. Regardless, all contributions for this project will be most welcome! Since both the correction factor for radiant elevation and the observing conditions change rapidly in the approach to morning twilight in early June, it is recommended that visual observers break their watches into short intervals (of the order of about 15-20 minutes), determining the limiting magnitude frequently for each interval. Observers at latitudes south of about $30^{\circ} \mathrm{N}$ are better placed because of the significantly poorer twilight conditions further north in June.

\section{June Boötids (170 JBO)}

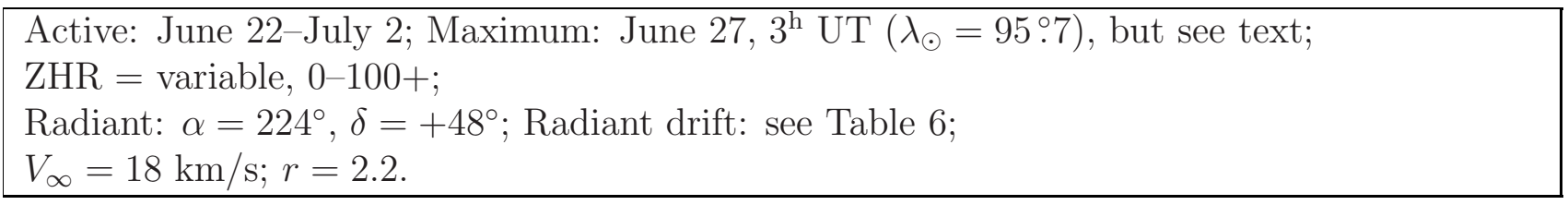

This source was reinstated on the Working List after its unexpected return of 1998, when ZHRs of $50-100+$ were visible for more than half a day. Another outburst of similar length, but with ZHRs of $\approx 20-50$ was observed on 2004 June 23, a date before definite June Boötid activity had been recorded previously. Consequently, the shower's start date was altered to try to ensure future rates so early are caught, and we encourage all observers to routinely monitor throughout the proposed period, in case of fresh outbursts. The return predicted in 2010 yielded ZHRs of less than 10 on June 23-24 which were not well confirmed. Prior to 1998, only three more probable returns had been detected, in 1916, 1921 and 1927, and with no significant reports between 1928 and 1997, it seemed likely these meteoroids no longer encountered Earth. The dynamics of the stream have been subjected to theoretical modelling which has improved our comprehension. The shower's parent, Comet 7P/Pons-Winnecke, has an orbit that now lies around 0.24 astronomical units outside the Earth's at its closest approach. Its latest perihelion passage occurred on 2015 January 30. The 1998 and 2004 events resulted from material ejected from the comet in the past which now lies on slightly different orbits to the comet itself. From mid-northerly latitudes the radiant is observable almost all night, but the prolonged - in some places continuous - twilight overnight keeps the useable time short. This year, the Moon reaches its last quarter on June 27, further reducing the undisturbed time. VID suggested some June Boötids may be visible in most years around June 20-25 (closer to full moon this year), but with activity largely negligible except near $\lambda_{\odot}=92^{\circ}$ (2016 June 23), radiating from an area about ten degrees south of the radiant found in 1998 and 2004, close to $\alpha=216^{\circ}, \delta=+38^{\circ}$. Mikhail Maslov finds that the Earth passes the 1921 trail within 0.00123 au on June $2300^{\mathrm{h}} 08^{\mathrm{m}}$ UT. Particles which may encounter the Earth are expected to be very small. So the radiant at $\alpha=203^{\circ}, \delta=+52^{\circ}$ will not produce visual activity (faint meteors plus moonlight) - but radar may detect signs of the trail. 


\section{$5 \quad$ July to September}

The ANT is the chief focus for visual attention during most of July, as its radiant area moves steadily through eastern Sagittarius, then across northern Capricornus into southwest Aquarius. Results suggest the Source may not be especially recognisable after the first few days though, as ZHRs for most of the month seem $<2$. Activity appears to improve somewhat, with ZHRs $\approx 2$ to 3, by late July and through the first half of August. The large ANT radiant area overlaps that of the minor $\boldsymbol{\alpha}$-Capricornids (001 CAP) in July-August, but the lower apparent velocity of the CAP may help observers still separate the two. The Southern $\boldsymbol{\delta}$-Aquariids (005 SDA) are strong enough, and the Piscis Austrinids (183 PAU) have a radiant distant enough from the ANT area, that both should be more easily separable from the ANT, particularly from the southern hemisphere. In 2016, the Moon (last quarter on Jul 26) will not disturb the period of highest rates from these southern radiants.

Contrary to this, the full moon on August 18 will then affect Perseid (007 PER) observations particularly after the peak. The effect is even stronger for the minor $\boldsymbol{\kappa}$-Cygnid (012 KCG) maximum this year, a shower which showed enhanced rates in 2014. ANT ZHRs will likely have dropped back below 2 again by late August, rising once more to $\approx 2-3$ by early September, as the radiant tracks on through Aquarius and into western Pisces. Conditions are perfect to check the usually-minor Aurigid (206 AUR) peak, due around 19 ${ }^{\mathrm{h}}$ UT on August 31. Waxing moon allows to follow the activity of the September $\varepsilon$-Perseids (208 SPE) as well.

$\varepsilon$-Eridanids (209 EER): Jérémie Vaubaillon's calculations have indicated that there may be some activity from the $\varepsilon$-Eridanids on 2016 September 12 near $17^{\mathrm{h}} 30^{\mathrm{m}}$ UT. The meteoroids are thought to have been released from comet $\mathrm{C} / 1854 \mathrm{~L} 1$ (Klinkerfues). The radiant is at $\alpha=57^{\circ}$, $\delta=-14^{\circ}$, and their atmospheric entry velocity of $59 \mathrm{~km} / \mathrm{s}$ is similar to that of the Perseids. The radiant first appears only in the moonless morning hours. As with many previous alerts, observations are needed to check what happens. Even a meteor count of 'zero' under good conditions would be a valuable result!

New Moon on October 1 allows attempts also for visual observers to catch some Daytime Sextantids (221 DSX) in the pre-dawn of late September. Remember that the Southern Taurids (002 STA) begin around September 10, effectively taking over the near-ecliptic activity from the ANT through to December.

For daylight radio observers, the high activity of May-June has waned, but there remain the $\gamma$-Leonids (203 GLE; peak due near August 25, 05 $\mathrm{hT}$, albeit not found in recent radio results), and the Sextantids (221 DSX; see below).

\section{Piscis Austrinids (183 PAU)}

Active: July 15-August 10; Maximum: July $28\left(\lambda_{\odot}=125^{\circ}\right) ; \mathrm{ZHR}=5$;

Radiant: $\alpha=341^{\circ}, \delta=-30^{\circ}$; Radiant drift: see Table 6 ;

$V_{\infty}=35 \mathrm{~km} / \mathrm{s} ; r=3.2$.

Very little information has been collected on the PAU in recent years, so the details on the shower are not well-confirmed, and it seems possible the ZHR may be a little optimistic. However, that impression could be due simply to the large amount of northern hemisphere summer data, and the almost complete lack of southern hemisphere winter results, on it. Observations are needed to establish the listed parameters. 


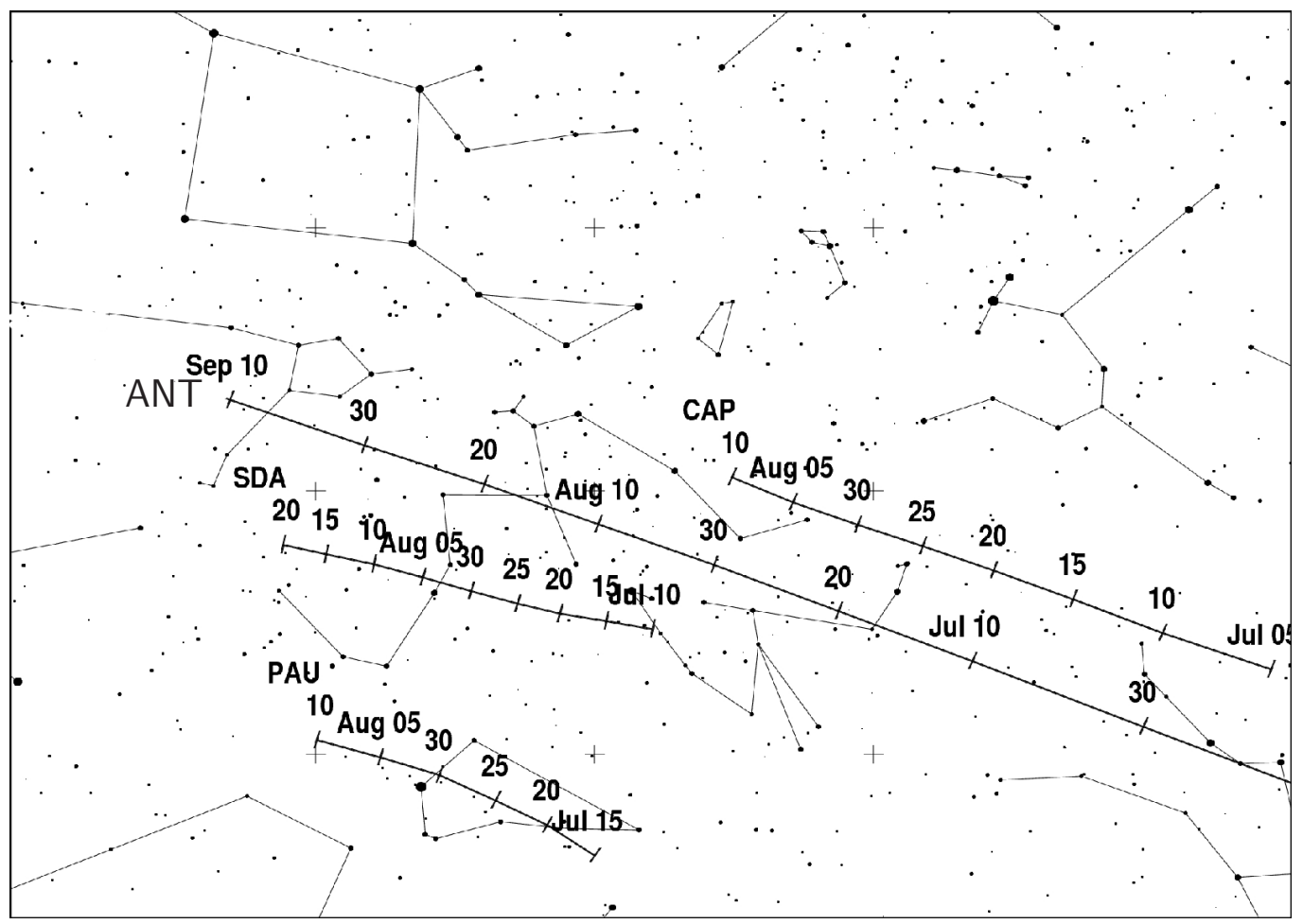

Southern $\delta$-Aquariids (005 SDA)

Active: July 12-August 23; Maximum: July $30\left(\lambda_{\odot}=127^{\circ}\right) ;$ ZHR $=16$;

Radiant: $\alpha=340^{\circ}, \delta=-16^{\circ}$; Radiant drift: see Table 6 ;

$V_{\infty}=41 \mathrm{~km} / \mathrm{s} ; r=2.8$.

Radio work can pick up the SDA as well, and indeed the shower has sometimes given a surprisingly strong radio signature. Visually, careful plotting is advised to help with accurate shower association. The SDA maximum may not be quite so sharp as the single date here could imply, with perhaps similar ZHRs and several sub-maxima between July 26 and 31, all equally favourable for dark-sky coverage this time.

$\alpha$-Capricornids (001 CAP)

Active: July 3-August 15; Maximum: July $30\left(\lambda_{\odot}=127^{\circ}\right)$; ZHR $=5$;

Radiant: $\alpha=307^{\circ}, \delta=-10^{\circ}$; Radiant drift: see Table 6 ;

$V_{\infty}=23 \mathrm{~km} / \mathrm{s} ; r=2.5$.

The CAP and SDA radiants were both definitely detected visually in former years, standing out against those much weaker ones supposed active in Capricornus-Aquarius then. Although the radiant of the CAP partly overlaps that of the large ANT region, the low CAP velocity should allow both video and visual observers to distinguish between the two sources. Frequently, bright and at times fireball-class shower meteors are seen. A minor enhancement of CAP ZHRs to $\approx 10$ was noted in 1995 by European IMO observers. Particularly higher ZHRs have been reported back in 1984. Recent results suggest the maximum may continue into July 31. 
Active: July 17-August 24; Maximum: August $12,13^{\mathrm{h}} 00^{\mathrm{m}}$ to $15^{\mathrm{h}} 30^{\mathrm{m}}$ UT (node at $\lambda_{\odot}=$ $140.0-140.1$ ), but see text; ZHR = 150;

Radiant: $\alpha=48^{\circ}, \delta=+58^{\circ}$; Radiant drift: see Table 6 ;

$V_{\infty}=59 \mathrm{~km} / \mathrm{s} ; r=2.2$.

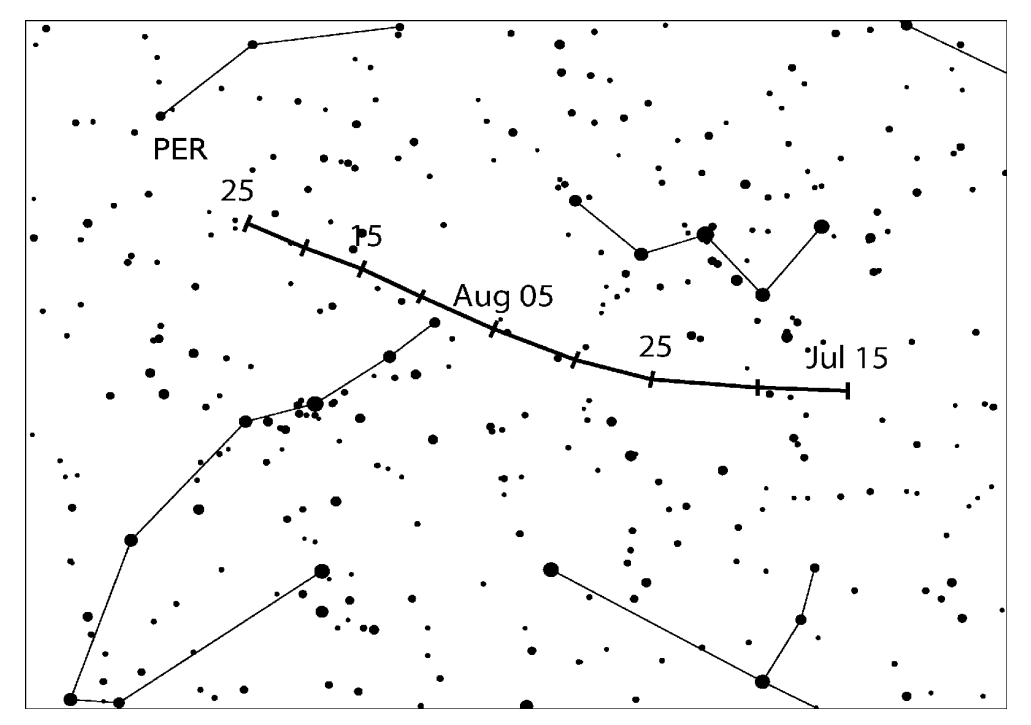

IMO observations (see WB pp. 32-36) found the timing of the mean or 'traditional' broad maximum varied between $\lambda_{\odot} \approx 139.8$ to 140.3 , equivalent to 2016 August $12,08^{\mathrm{h}}$ to $22^{\mathrm{h}} \mathrm{UT}$. The orbital period of the parent comet 109P/Swift-Tuttle is about 130 years. The Perseids produced strong activity from a primary maximum throughout the 1990s. Enhanced activity ahead of the usual maximum was last seen in 2007 at $\lambda_{\odot}=139.68$ and behind the nodal position in 2008 at $\lambda_{\odot}=140.55$.

Results from Mikhail Maslov and Esko Lyytinen indicate that we will cross a part of the stream which was shifted closer to the Earth's orbit by Jupiter in 2016. As a consequence, the background ZHR may reach a level of 150-160.

Already on August 11, 22 $34^{\mathrm{m}}$ UT the Earth should encounter small meteoroids of the 1revolution trail causing an increase of the ZHR by about 10 . At $23^{\mathrm{m}} 23^{\mathrm{m}}$ UT brighter meteors of the 4-revolution trail are expected.

According to calculations of Jérémie Vaubaillon, the densest part of the stream dominated by meteoroids of the 2-revolution trail is crossed between August $12,00^{\mathrm{h}}$ to $04^{\mathrm{h}} \mathrm{UT}\left(\lambda_{\odot}=139.49-\right.$ 139 .66), well before the broad nodal maximum.

Neither these predictions, nor the nodal crossing time given in the box above, are guarantees of what will occur! The Moon reaches its first quarter on August 10 and is located in the southern section of the ecliptic. Dark skies are then restricted to the post-midnight period. Sites at mid-northern latitudes are more favourable for Perseid observing, as from here, the shower's radiant can be usefully observed from $22^{\mathrm{h}}-23^{\mathrm{h}}$ local time onwards, gaining altitude throughout the night. The (first) August 12 peak time especially favours European longitudes, while the (later) near-nodal part of the 'traditional' maximum interval would be best-viewed from North American sites, assuming either takes place when expected. All forms of observing can be carried out on the shower, though regrettably, it cannot be properly viewed from most of the southern hemisphere. 
Aurigids (206 AUR)

Active: August 28-September 5; Maximum: August 31, $19^{\mathrm{h}}$ UT $\left(\lambda_{\odot}=158.6\right)$; ZHR $=6$;

Radiant: $\alpha=91^{\circ}, \delta=+39^{\circ}$; Radiant drift: see Table 6 ;

$V_{\infty}=66 \mathrm{~km} / \mathrm{s} ; r=2.5$.

This northern-hemisphere shower has produced short, unexpected, outbursts at times, with EZHRs of $\approx$ 30-40 recorded in 1935, 1986 and 1994, although it has not been monitored regularly until very recently, so other events may have been missed. Only three watchers in total covered the 1986 and 1994 outbursts, for instance! While badly moonlit, the first predicted outburst happened roughly as expected in 2007, producing short-lived EZHRs of $\approx 130$, with many bright meteors. Radio data suggested there was a 'tail' to that event where more faint meteors continued for maybe an hour after the strongest peak, but visual observers could not confirm this, probably due to the moonlit sky. The Aurigid radiant reaches a useful elevation only after $\approx 01^{\mathrm{h}}$ local time. For 2016, there are no predictions for enhanced rates from this source, but new Moon on September 1 guarantees perfect conditions to check.

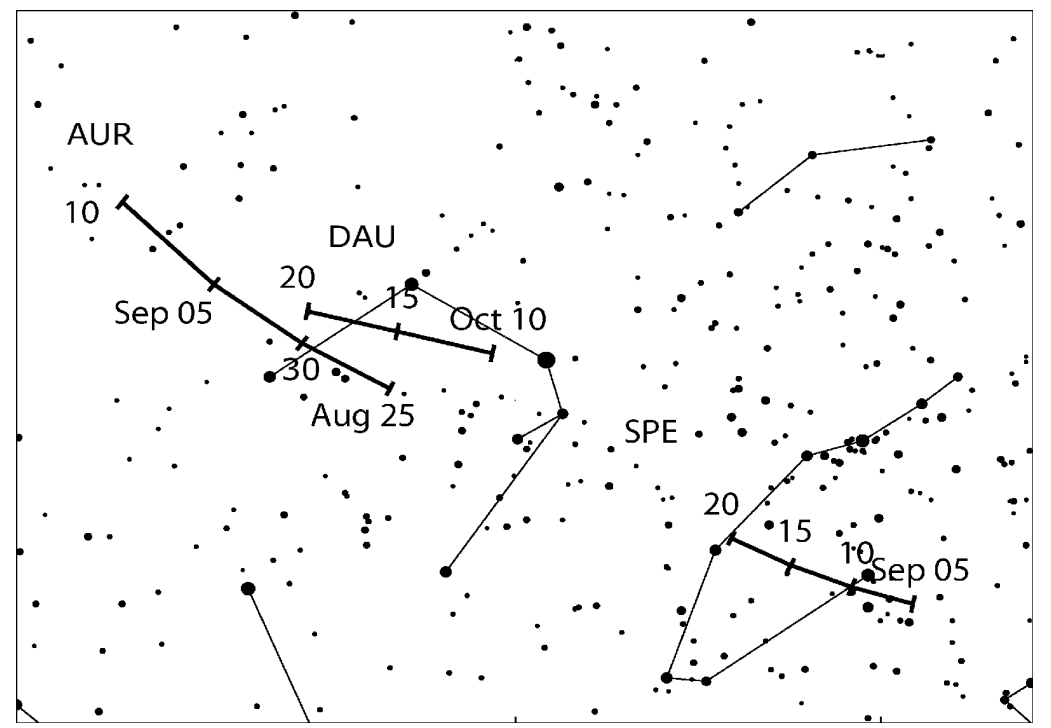

September $\varepsilon$-Perseids (208 SPE)

Active: September 5-21; Maximum: September 9, $04^{\mathrm{h}} \mathrm{UT}\left(\lambda_{\odot}=166.7\right)$, but see text;

$\mathrm{ZHR}=5$;

Radiant: $\alpha=48^{\circ}, \delta=+40^{\circ}$; Radiant drift: see Table 6 ;

$V_{\infty}=64 \mathrm{~km} / \mathrm{s} ; r=3.0$.

First quarter Moon on September 9 should be little hindrance for observing this primarily northern-hemisphere shower's maximum as it leaves the post-midnight period without moonlight. The radiant area is well on-view all night from about $22^{\mathrm{h}}-23^{\mathrm{h}}$ local time for mid-northern locations. This radiant was apparently that responsible for producing an unexpected outburst of swift, bright meteors on 2008 September 9, between roughly $\lambda_{\odot}=166.894-166.921$, and another bright-meteor event with a very sharp peak at $\lambda_{\odot}=167^{\circ} .188$ in 2013. Esko Lyytinen's modelling has suggested the next really impressive SPE return may not be before 2040. For completeness, the repeat times for the recent outburst intervals converted to 2016 would both be on September 9 , respectively around $9^{\mathrm{h}} \mathrm{UT}$ around $17^{\mathrm{h}} \mathrm{UT}$. There are no predictions of higher activity in 2016. 
Daytime Sextantids (221 DSX)

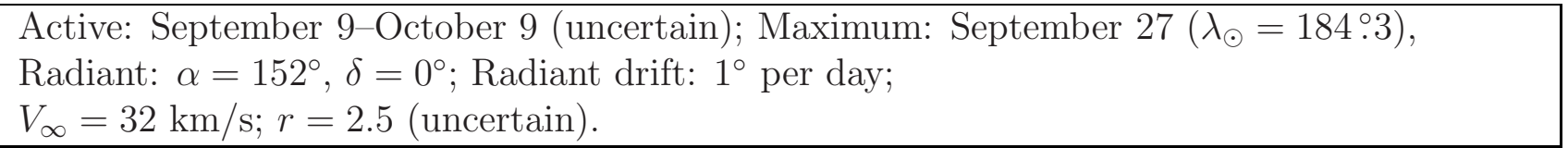

New Moon on October 1 helps visual observers to catch some Sextantids in the pre-dawn of late September to early October as part of the IMO project to collect and pool data obtained by all techniques for this shower and the Arietids in early June. The DSX radiant is roughly $30^{\circ}$ west of the Sun. Because it lies close to the equator and the activity period is shortly after the equinox, the chances to contribute results are almost equally good for observers in either hemisphere. As with the Arietids, both the radiant elevation correction and the observing conditions change rapidly as morning twilight approaches. Hence visual observers should report their data in short intervals, no longer than about 15-20 minutes, determining the limiting magnitude frequently during each period. The timing, and even the date, of the Sextantid maximum is uncertain. Recent radio data have indicated that it may occur a day earlier than expected, and it seems plausible several minor radio peaks in early October may also be due to this source.

\section{October to December}

During the last quarter of the year most significant showers are badly affected by moonlight.

October Camelopardalids (281 OCT): Short-lived video outbursts were recorded in 2005 and 2006 on October $5 / 6\left(\right.$ near $\left.\lambda_{\odot} 193^{\circ}\right)$ from a north-circumpolar radiant at $\alpha \approx 166^{\circ}, \delta \approx+79^{\circ}$. The meteors showed an atmospheric velocity of $47 \mathrm{~km} / \mathrm{s}$. The 2005 event (only) was recorded very weakly by radio, but no visual results confirmed either occurrence, and no recurrence was reported in 2007, 2008, 2011, 2012 or during the extremely favourable return timing for European observers in 2013. Weak video rates were claimed detected near the 2009 and 2010 repeat times, but again, no other method confirmed these, and the shower was not found by the full ten-year VID analysis. Confusingly, this apparently occasional minor shower has become known in some places as the "October Camelopardalids" or OCA, despite the radiant's location, and in fact the name was already used for a probably different shower, first detected by radar back in the 1970s. The active interval suggested by the video data lies between $\lambda_{\odot} \approx 192^{\circ} .5^{-}$ 192.8 , equivalent to 2016 October $5,14^{\mathrm{h}}$ to $21^{\mathrm{h}} \mathrm{UT}$, and has little disturbance from the waxing Moon. If the active interval remains the same, parts of it should be best-observed from western Asia further westwards to Europe. Esko Lyytinen has pointed out that the case of the October Camelopardalids is not quite clear: "it seems that the orbit is of long period nature. After the 2005 observation was concluded to be an outburst of the 1-revolution trail, while it now appears to be an annual shower. Either this trail is a lot wider than a typical long period 1-revolution trail, or we have not yet encountered the trail center. There might be (surprise) encounters in different years. In the year 2016 the calculated trail position is very much the same as in 2005 . So in 2016 I expect an about similar level outburst (but probably not much stronger) than the one observed in 2005. I think that some moderate level activity is quite probable in 2016. The predicted position is at $\lambda_{\odot} 192.56$, corresponding to 2016 October $5,14^{\mathrm{h}} 45^{\mathrm{m}}$ UT."

The Draconid (009 DRA) maximum on October 8 occurs together with the first quarter moon which illuminates the evening hours with the highest radiant position. However, there are no predictions for any rate enhancement in 2016. For the maximum of the $\boldsymbol{\delta}$-Aurigids (224 DAU) (maximum October 11) the morning hours when the radiant area is highest in the sky remain moon-free. The Orionid (008 ORI) maximum on October 21 coincides with the last 
quarter Moon located quite close to the radiant at this time spoiling all optical observations. The Leonids (013 LEO) are even worse with their maximum on November 17 just three days after full Moon. For both showers the model calculations do not suggest any rate enhancement, however. Although the activity of the $\boldsymbol{\alpha}$-Monocerotids (246 AMO) is expected to be at the detection limit, all observations of this shower are welcome. The last quarter Moon on November 21 leaves the pre-midnight hours dark, but the radiant reaches useful elevations only towards local midnight.

The November Orionids (250 NOO) have been added to the list because they are actually stronger than several showers listed and are detected regularly in video data. Later, the minor Monocerotids (019 MON) can be observed prior to their maximum on December 8 which falls two days after the first quarter Moon while the $\boldsymbol{\sigma}$-Hydrids (016 HYD) reach their maximum (December 11) only about 2 days before full Moon.

The ANT starts the quarter effectively inactive in favour of the Taurids, resuming only around December 10, as the Northern Taurids fade away, from a radiant centre that tracks across southern Gemini during later December, likely producing ZHRs $<2$. While the period of highest Southern Taurid (002 STA) activity around October 10 can be observed with little moonlight interference, the maximum of the Northern Taurids (017 NTA) falls near the full Moon (November 14).

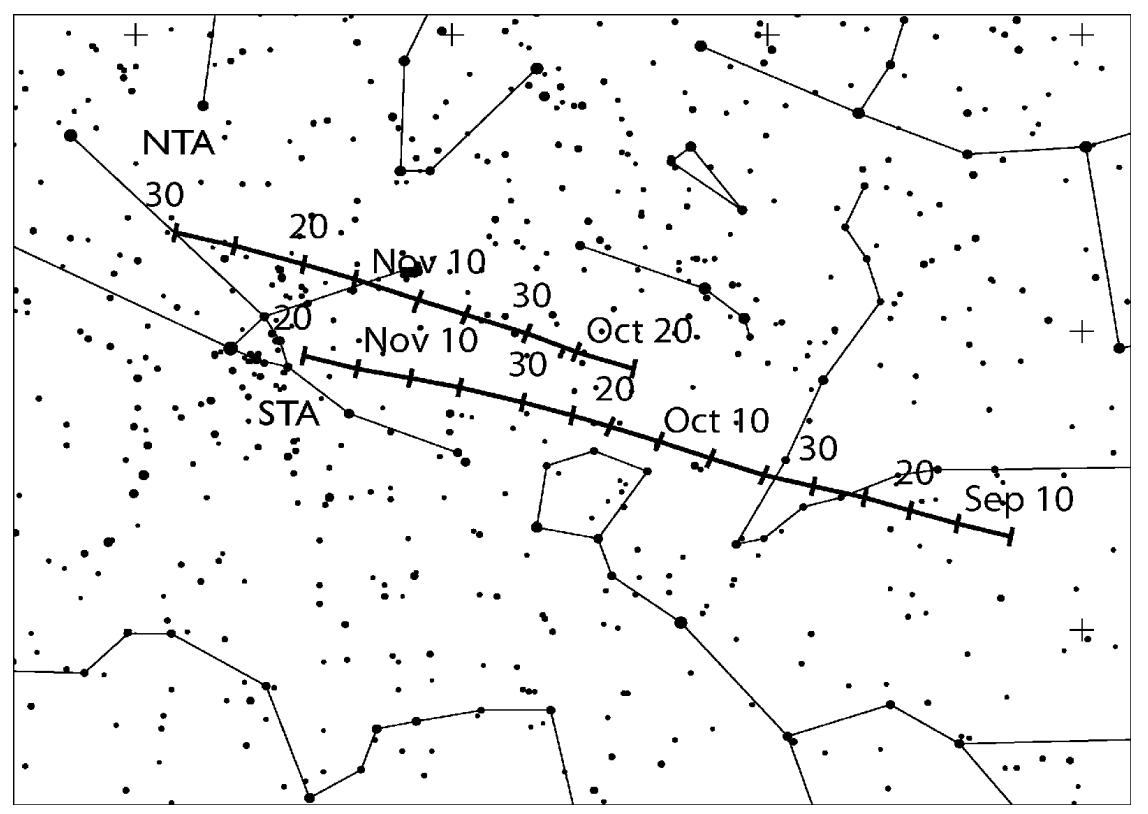

Southern Taurids (002 STA)

Active: September 10-November 20; Maximum: October $10\left(\lambda_{\odot}=197^{\circ}\right) ; \mathrm{ZHR}=5$;

Radiant: $\alpha=32^{\circ}, \delta=+9^{\circ}$; Radiant drift: see Table 6;

$V_{\infty}=27 \mathrm{~km} / \mathrm{s} ; r=2.3$.

This stream, with its Northern counterpart, forms part of the complex associated with Comet $2 \mathrm{P} /$ Encke with a large and diffuse radiant. For shower association, assume the radiant to be an oval area, $\approx 20^{\circ} \times 10^{\circ}, \alpha \times \delta$, centred on the radiant position for any given date. The Taurid activity overall dominates the Antihelion Source area's during the northern autumn, so that all meteors from this region are associated to one of the Taurid radiants. The brightness and relative slowness of many Taurid meteors makes them ideal targets for still-imaging, while these factors coupled with low, steady, Taurid rates makes them excellent subjects for newcomers to practice their visual plotting techniques on. The southern branch reaches its peak about a 
month before the northern one. Its near-ecliptic radiant means all meteoricists can observe the STA, albeit northern hemisphere observers are somewhat better-placed, as here suitable radiant zenith distances persist for much of the night. Even in the southern hemisphere however, 3-5 hours' watching around local midnight is possible with Taurus well clear of the horizon. There are no predictions for a Taurid swarm as there was for 2015.

\section{$\delta$-Aurigids (224 DAU)}

Active: October 10-18; Maximum: October $11\left(\lambda_{\odot}=198^{\circ}\right) ; \mathrm{ZHR}=2$;

Radiant: $\alpha=84^{\circ}, \delta=+44^{\circ}$; Radiant drift: see Table 6 ;

$V_{\infty}=64 \mathrm{~km} / \mathrm{s} ; r=3.0$.

The weakest of the three known near-Auriga-Perseus showers of late August to October, visual observers seem to have struggled to properly identify this minor source previously, and its current parameters are based on a detailed review of IMO video data since the late 1990s. The Moon reaches first quarter on October 9 leaving the morning hours dark. The radiant area is visible chiefly from the northern hemisphere, from where it can be properly observed after local midnight. The radiant drift is shown together with the AUR and SPE on page 13.

\section{November Orionids (250 NOO)}

Active: November 14-December 6; Maximum: November $28\left(\lambda_{\odot}=246^{\circ}\right)$; ZHR $=3$;

Radiant: $\alpha=91^{\circ}, \delta=+16^{\circ}$; Radiant drift: see Table 6 ;

$V_{\infty}=41 \mathrm{~km} / \mathrm{s} ; r=3.0$.

This shower is easily detected in video data. The detailed analysis reveals that there are two consecutive, very similar showers whose activity intervals overlap by only two degrees in solar longitude: the first is the November Orionids (250 NOO), followed by the Monocerotids (019 MON). In the last days of November the shower is the strongest source in the sky. The radiant is located in northern Orion, $4^{\circ}$ north of $\alpha$ Orionis. This location is close to the Northern Taurids, but far enough east to be distinguishable. The faster velocity of the November Orionids should help distinguish these meteors from the slower Taurids. The radiant culminates near $2^{\mathrm{h}}$ local time, but is above the horizon for most of the night. New Moon on November 29 offers best circumstances to collect data.

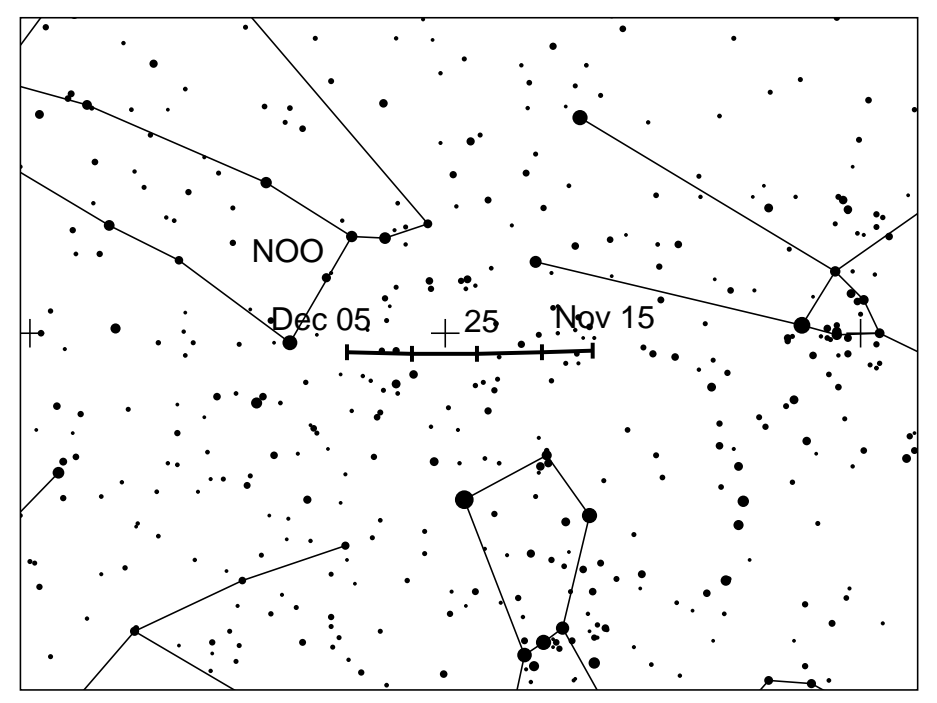


Phoenicids (254 PHO)

Active: November 28-December 9; Maximum: December 2, $0^{\mathrm{h}} \mathrm{UT}\left(\lambda_{\odot}=250\right.$.0);

$\mathrm{ZHR}=$ variable, usually none, see text;

Radiant: $\alpha=18^{\circ}, \delta=-53^{\circ}$; Radiant drift: see Table 6 ;

$V_{\infty}=18 \mathrm{~km} / \mathrm{s} ; r=2.8$.

Only one impressive Phoenicid return has been reported, that of its discovery in 1956, when the EZHR was probably $\approx 100$, possibly with several peaks spread over a few hours. Recent significant activity was observed on 2014 December 1. This was predicted by Sato and Watanabe who find that future activity may occur only in 2019. Jérémie Vaubaillon's modelling shows traces of possible weak and scattered activity near December 2 around $0^{\mathrm{h}}$ UT. As the date is shortly after new moon, observers should check for possible Phoenicids. From the southern hemisphere (only), the Phoenicid radiant culminates at dusk, remaining well on view for most of the night. Phoenicids are extremely slow meteors.
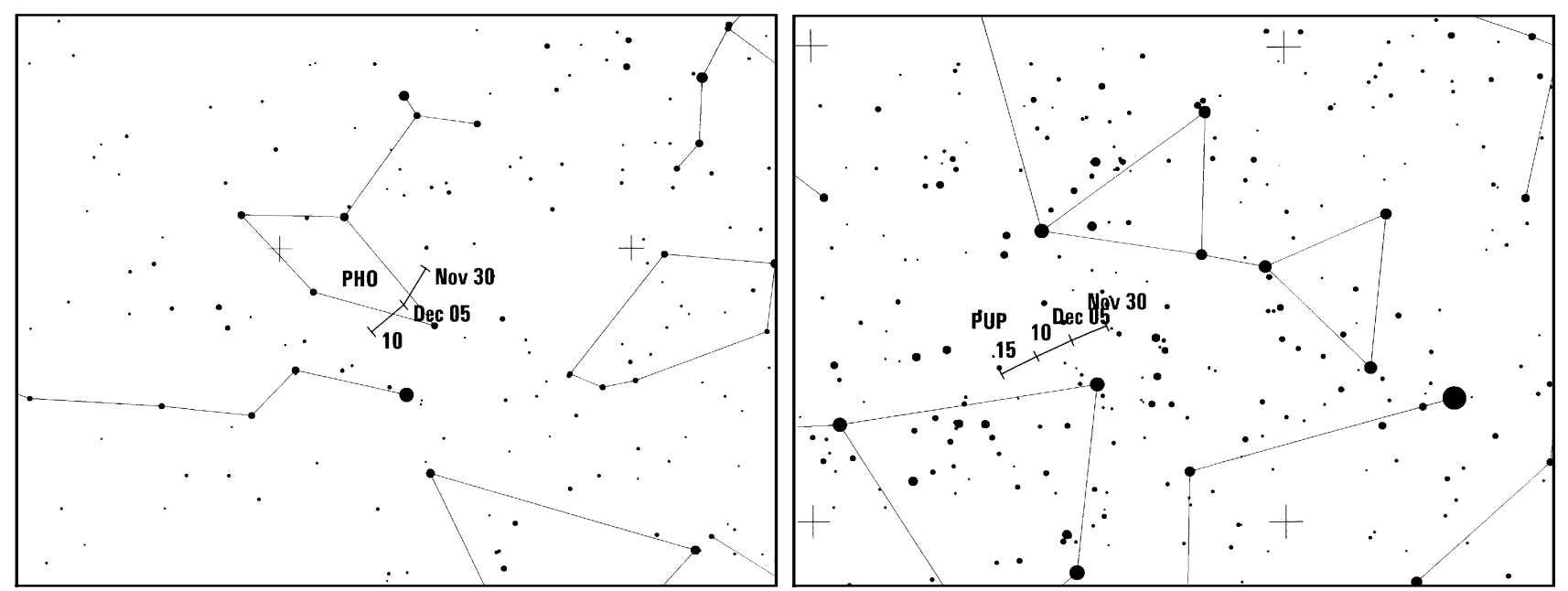

Puppid-Velids (301 PUP)

Active: December 1-15; Maximum: December $\approx 7\left(\lambda_{\odot} \approx 255^{\circ}\right) ; \mathrm{ZHR} \approx 10$;

Radiant: $\alpha=123^{\circ}, \delta=-45^{\circ}$; Radiant drift: see Table 6 ;

$V_{\infty}=40 \mathrm{~km} / \mathrm{s} ; r=2.9$.

This is a complex system of poorly-studied showers, visible chiefly to those south of the equator. Up to ten sub-streams have been proposed (301 PUP representing an "average" position), with radiants so tightly clustered, visual observing cannot readily separate them. Imaging work would thus be sensible, or very careful visual plotting. The activity is poorly-established, though the higher rates seem to occur in early to mid December (first quarter Moon on December 7 this year). Some PUP activity may occur from late October to late January, however. Most PUP meteors are faint, but occasional bright fireballs, notably around the suggested maximum, have been reported. In the southern hemipshere, the radiant area is on-view all night, highest towards dawn. 
Ursids (015 URS)

Active: December 17-26; Maximum: December 22, $09^{\mathrm{h}} \mathrm{UT}\left(\lambda_{\odot}=270\right.$ ?7);

$\mathrm{ZHR}=10$ (occasionally variable up to 50 );

Radiant: $\alpha=217^{\circ}, \delta=+76^{\circ}$; Radiant drift: see Table 6 ;

$V_{\infty}=33 \mathrm{~km} / \mathrm{s} ; r=3.0$.

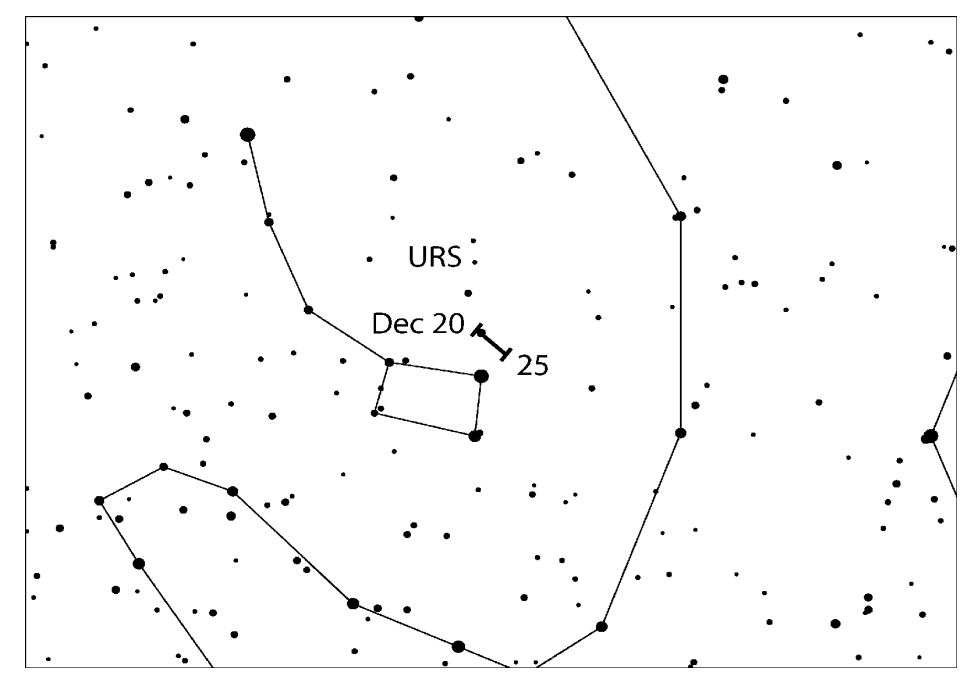

A very poorly-observed northern hemisphere shower, but one which has produced at least two major outbursts in the past 70 years, in 1945 and 1986. Several lesser rate enhancements have been reported as well, most recently from 2006-2008 inclusive which were probably influenced by the relative proximity of the shower's parent comet, 8P/Tuttle, last at perihelion in January 2008. Other events could have been missed easily. No unusually strong activity had been forecast for the 2016 shower when this Calendar was being prepared although Jérémie Vaubaillon's modelling has hinted that weak activity could be present in the nights December 22/23 (more likely) and $23 / 24$ close to $0^{\mathrm{h}}$ UT on each occasion. The Ursid radiant is circumpolar from most northern sites, so fails to rise for most southern ones, though it culminates after daybreak, and is highest in the sky later in the night. The waning Moon, last quarter on December 21, will leave the first half of the night (with lower radiant elevation) undisturbed for near-maximum observations.

\section{Radiant sizes and meteor plotting for visual observers}

by Rainer Arlt

If you are not observing during a major-shower maximum, it is essential to associate meteors with their radiants correctly, since the total number of meteors will be small for each source. Meteor plotting allows shower association by more objective criteria after your observation than the simple imaginary back-prolongation of paths under the sky. With meteors plotted on gnomonic maps, you can trace them back to their radiants by extending their straight line paths. If a radiant lies on another chart, you should find common stars on an adjacent chart to extend this back-prolongation correctly.

How large a radiant should be assumed for shower association? The real physical radiant size is very small, but visual plotting errors cause many true shower meteors to miss this real radiant area. Thus we have to assume a larger effective radiant to allow for these errors. Unfortunately, 
as we enlarge the radiant, so more and more sporadic meteors will appear to line up accidentally with this region. Hence we have to apply an optimum radiant diameter to compensate for the plotting errors loss, but which will not then be swamped by sporadic meteor pollution. Table 1 gives this optimum diameter as a function of the distance of the meteor from the radiant.

Table 1. Optimum radiant diameters to be assumed for shower association of minor-shower meteors as a function of the radiant distance $D$ of the meteor.

\begin{tabular}{|cc|}
\hline$D$ & optimum diameter \\
\hline $15^{\circ}$ & $14^{\circ}$ \\
$30^{\circ}$ & $17^{\circ}$ \\
$50^{\circ}$ & $20^{\circ}$ \\
$70^{\circ}$ & $23^{\circ}$ \\
\hline
\end{tabular}

Note that this radiant diameter criterion applies to all shower radiants except those of the Southern and Northern Taurids, and the Antihelion Source, all of which have notably larger radiant areas. The optimum $\alpha \times \delta$ size to be assumed for each radiant of the two Taurid showers is instead $20^{\circ} \times 10^{\circ}$, while that for the Antihelion Source is still larger, at $30^{\circ} \times 15^{\circ}$.

Path-direction is not the only criterion for shower association. The angular velocity of the meteor should match the expected speed of the given shower meteors according to their geocentric velocities. Angular velocity estimates should be made in degrees per second $(\% / \mathrm{s})$. To do this, make the meteors you see move for one second in your imagination at the speed you saw them. The path length of this imaginary meteor is the angular velocity in $\%$ s. Note that typical speeds are in the range $3 \%$ s to $25^{\circ} / \mathrm{s}$. Typical errors for such estimates are given in Table 2.

Table 2. Error limits for the angular velocity.

\begin{tabular}{|l|rrrrr|}
\hline angular velocity [\%/s] & 5 & 10 & 15 & 20 & 30 \\
permitted error [\% $/ \mathrm{s}]$ & 3 & 5 & 6 & 7 & 8 \\
\hline
\end{tabular}

If you find a meteor in your plots which passes the radiant within the diameter given by Table 1 , check its angular velocity. Table 3 gives the angular speeds for a few geocentric velocities, which can then be looked up in Table 5 for each shower.

Table 3. Angular velocities as a function of the radiant distance of the meteor $(D)$ and the elevation of the meteor above the horizon $(h)$ for three different geocentric velocities $\left(V_{\infty}\right)$. All velocities are in $\%$ s.

\begin{tabular}{ccccccccccccccccc}
\hline$h \backslash D$ & \multicolumn{4}{c}{$V_{\infty}=25 \mathrm{~km} / \mathrm{s}$} & \multicolumn{4}{c}{$V_{\infty}=40 \mathrm{~km} / \mathrm{s}$} & \multicolumn{4}{c}{$V_{\infty}=60 \mathrm{~km} / \mathrm{s}$} \\
& $10^{\circ}$ & $20^{\circ}$ & $40^{\circ}$ & $60^{\circ}$ & $90^{\circ}$ & $10^{\circ}$ & $20^{\circ}$ & $40^{\circ}$ & $60^{\circ}$ & $90^{\circ}$ & $10^{\circ}$ & $20^{\circ}$ & $40^{\circ}$ & $60^{\circ}$ & $90^{\circ}$ \\
\hline $10^{\circ}$ & 0.4 & 0.9 & 1.6 & 2.2 & 2.5 & 0.7 & 1.4 & 2.6 & 3.5 & 4.0 & 0.9 & 1.8 & 3.7 & 4.6 & 5.3 \\
$20^{\circ}$ & 0.9 & 1.7 & 3.2 & 4.3 & 4.9 & 1.4 & 2.7 & 5.0 & 6.8 & 7.9 & 1.8 & 3.5 & 6.7 & 9.0 & 10 \\
$40^{\circ}$ & 1.6 & 3.2 & 5.9 & 8.0 & 9.3 & 2.6 & 5.0 & 9.5 & 13 & 15 & 3.7 & 6.7 & 13 & 17 & 20 \\
$60^{\circ}$ & 2.2 & 4.3 & 8.0 & 11 & 13 & 3.5 & 6.8 & 13 & 17 & 20 & 4.6 & 9.0 & 17 & 23 & 26 \\
$90^{\circ}$ & 2.5 & 4.9 & 9.3 & 13 & 14 & 4.0 & 7.9 & 15 & 20 & 23 & 5.3 & 10 & 20 & 26 & 30 \\
\hline
\end{tabular}




\section{Abbreviations}

- $\alpha, \delta$ : Coordinates for a shower's radiant position, usually at maximum. $\alpha$ is right ascension, $\delta$ is declination. Radiants drift across the sky each day due to the Earth's own orbital motion around the Sun, and this must be allowed for using the details in Table 6 for nights away from the listed shower maxima.

- $r$ : The population index, a term computed from each shower's meteor magnitude distribution. $r=2.0-2.5$ implies a larger fraction of brighter meteors than average, while $r$ above 3.0 is richer in fainter meteors than average.

- $\lambda_{\odot}$ : Solar longitude, a precise measure of the Earth's position on its orbit which is not dependent on the vagaries of the calendar. All $\lambda_{\odot}$ are given for the equinox 2000.0.

- $V_{\infty}$ : Atmospheric or apparent meteoric velocity, given in $\mathrm{km} / \mathrm{s}$. Velocities range from about $11 \mathrm{~km} / \mathrm{s}$ (very slow) to $72 \mathrm{~km} / \mathrm{s}$ (very fast). $40 \mathrm{~km} / \mathrm{s}$ is roughly medium speed.

- ZHR: Zenithal Hourly Rate, a calculated maximum number of meteors an ideal observer would see in perfectly clear skies with the shower radiant overhead. This figure is given in terms of meteors per hour. Where meteor activity persisted at a high level for less than an hour, or where observing circumstances were very poor, an estimated ZHR (EZHR) is used, which is less accurate than the normal ZHR.

\section{Tables: lunar and shower data}

Table 4. Lunar phases for 2016.

\begin{tabular}{llll}
\hline New Moon & First Quarter & Full Moon & Last Quarter \\
\hline & & & January 2 \\
January 10 & January 16 & January 24 & February 1 \\
February 8 & February 15 & February 22 & March 1 \\
March 9 & March 15 & March 23 & March 31 \\
April 7 & April 14 & April 22 & April 30 \\
May 6 & May 13 & May 21 & May 29 \\
June 5 & June 12 & June 20 & June 27 \\
July 4 & July 12 & July 19 & July 26 \\
August 2 & August 10 & August 18 & August 25 \\
September 1 & September 9 & September 16 & September 23 \\
October 1 & October 9 & October 16 & October 22 \\
October 30 & November 7 & November 14 & November 21 \\
November 29 & December 7 & December 14 & December 21 \\
December 29 & & & \\
\hline
\end{tabular}


Table 5. Working List of Visual Meteor Showers. Details in this Table were correct according to the best information available in May 2015, with maximum dates accurate only for 2016. Except for the Antihelion Source, all other showers are listed in order of their maximum solar longitude. The parenthesized maximum date for the Puppids-Velids indicates a reference date for the radiant only, not necessarily a true maximum. Some showers have ZHRs that vary from year to year. The most recent reliable figure is given here, except for possibly periodic showers which are noted as 'Var' = variable. For more information, contact the IMO's Visual Commission or check the updates published e.g. in the IMO Journal WGN.

\begin{tabular}{|c|c|c|c|c|c|c|c|c|c|c|}
\hline \multirow[t]{2}{*}{ Shower } & \multirow{2}{*}{\multicolumn{2}{|c|}{ Activity }} & \multicolumn{3}{|c|}{ Maximum } & \multicolumn{2}{|c|}{ Radiant } & \multirow{2}{*}{$\begin{array}{l}V_{\infty} \\
\mathrm{km} / \mathrm{s}\end{array}$} & \multirow[t]{2}{*}{$r$} & \multirow[t]{2}{*}{ ZHR } \\
\hline & & & Dat & & $\lambda_{\odot}$ & $\alpha$ & $\delta$ & & & \\
\hline Antihelion Source (ANT) & Dec & 10-Sep 10 & \multicolumn{3}{|c|}{$\begin{array}{l}\text { March-April, } \\
\text { late May, late June }\end{array}$} & \multicolumn{2}{|c|}{ see Table 6} & 30 & 3.0 & 4 \\
\hline Quadrantids (010 QUA) & Dec & 28-Jan 12 & Jan & 04 & $283^{\circ} .16$ & $230^{\circ}$ & $+49^{\circ}$ & 41 & 2.1 & 120 \\
\hline$\alpha$-Centaurids (102 ACE) & Jan & $28-$ Feb 21 & Feb & 08 & 319.2 & $210^{\circ}$ & $-59^{\circ}$ & 56 & 2.0 & 6 \\
\hline$\gamma$-Normids (118 GNO) & Feb & 25-Mar 28 & Mar & 14 & $354^{\circ}$ & $239^{\circ}$ & $-50^{\circ}$ & 56 & 2.4 & 6 \\
\hline Lyrids (006 LYR) & Apr & 16-Apr 25 & Apr & 22 & 32.32 & $271^{\circ}$ & $+34^{\circ}$ & 49 & 2.1 & 18 \\
\hline$\pi$-Puppids (137 PPU) & Apr & 15-Apr 28 & Apr & 23 & 33.5 & $110^{\circ}$ & $-45^{\circ}$ & 18 & 2.0 & Var \\
\hline$\eta$-Aquariids (031 ETA) & Apr & 19-May 28 & May & 05 & 45.5 & $338^{\circ}$ & $-01^{\circ}$ & 66 & 2.4 & 40 \\
\hline$\eta$-Lyrids (145 ELY) & May & 03-May 14 & May & 08 & 48.0 & $287^{\circ}$ & $+44^{\circ}$ & 43 & 3.0 & 3 \\
\hline Dayt. Arietids (171 ARI) & May & $14-$ Jun 24 & Jun & 07 & 76.6 & $44^{\circ}$ & $+24^{\circ}$ & 38 & 2.8 & 50 \\
\hline June Bootids (170 JBO) & Jun & 22-Jul 02 & Jun & 27 & 95.7 & $224^{\circ}$ & $+48^{\circ}$ & 18 & 2.2 & Var \\
\hline Piscis Austr. (183 PAU) & Jul & 15-Aug 10 & Jul & 28 & $125^{\circ}$ & $341^{\circ}$ & $-30^{\circ}$ & 35 & 3.2 & 5 \\
\hline S. $\delta$-Aquariids (005 SDA) & Jul & $12-$ Aug 23 & Jul & 30 & $127^{\circ}$ & $340^{\circ}$ & $-16^{\circ}$ & 41 & 3.2 & 16 \\
\hline$\alpha$-Capricornids (001 CAP) & Jul & 03-Aug 15 & Jul & 30 & $127^{\circ}$ & $307^{\circ}$ & $-10^{\circ}$ & 23 & 2.5 & 5 \\
\hline Perseids (007 PER) & Jul & 17-Aug 24 & Aug & 12 & $140 \stackrel{\circ}{0}$ & $48^{\circ}$ & $+58^{\circ}$ & 59 & 2.2 & 150 \\
\hline$\kappa$-Cygnids (012 KCG) & Aug & $03-$ Aug 25 & Aug & 17 & $145^{\circ}$ & $286^{\circ}$ & $+59^{\circ}$ & 25 & 3.0 & 3 \\
\hline Aurigids (206 AUR) & Aug & 28-Sep 05 & Aug & 31 & 158.6 & $91^{\circ}$ & $+39^{\circ}$ & 66 & 2.5 & 6 \\
\hline Sept. $\varepsilon$-Perseids (208 SPE) & Sep & 05-Sep 21 & Sep & 09 & 166.7 & $48^{\circ}$ & $+40^{\circ}$ & 64 & 3.0 & 5 \\
\hline Dayt. Sextantids (221 DSX) & Sep & 09-Oct 09 & Sep & 27 & 184.3 & $152^{\circ}$ & $+00^{\circ}$ & 32 & 2.5 & 5 \\
\hline Draconids (009 DRA) & Oct & 06-Oct 10 & Oct & 08 & 195.4 & $262^{\circ}$ & $+54^{\circ}$ & 20 & 2.6 & Var \\
\hline S. Taurids (002 STA) & Sep & $10-$ Nov 20 & Oct & 10 & $197^{\circ}$ & $32^{\circ}$ & $+09^{\circ}$ & 27 & 2.3 & 5 \\
\hline$\delta$-Aurigids（224 DAU) & Oct & 10-Oct 18 & Oct & 11 & $198^{\circ}$ & $84^{\circ}$ & $+44^{\circ}$ & 64 & 3.0 & 2 \\
\hline$\varepsilon$-Geminids (023 EGE) & Oct & $14-$ Oct 27 & Oct & 18 & $205^{\circ}$ & $102^{\circ}$ & $+27^{\circ}$ & 70 & 3.0 & 3 \\
\hline Orionids (008 ORI) & Oct & 02-Nov 07 & Oct & 21 & $208^{\circ}$ & $95^{\circ}$ & $+16^{\circ}$ & 66 & 2.5 & 15 \\
\hline Leonis Minorids (022 LMI) & Oct & 19-Oct 27 & Oct & 24 & $211^{\circ}$ & $162^{\circ}$ & $+37^{\circ}$ & 62 & 3.0 & 2 \\
\hline N. Taurids (017 NTA) & Oct & $20-\operatorname{Dec} 10$ & Nov & 12 & $230^{\circ}$ & $58^{\circ}$ & $+22^{\circ}$ & 29 & 2.3 & 5 \\
\hline Leonids (013 LEO) & Nov & $06-$ Nov 30 & Nov & 17 & 235.27 & $152^{\circ}$ & $+22^{\circ}$ & 71 & 2.5 & 15 \\
\hline$\alpha$-Monocerotids (246 AMO) & Nov & $15-$ Nov 25 & Nov & 21 & 239.32 & $117^{\circ}$ & $+01^{\circ}$ & 65 & 2.4 & Var \\
\hline Nov. Orionids (250 NOO) & Nov & 13-Dec 06 & Nov & 28 & $246^{\circ}$ & $91^{\circ}$ & $+16^{\circ}$ & 44 & 3.0 & 3 \\
\hline Phoenicids (254 PHO) & Nov & 28-Dec 09 & Dec & 02 & $250 \stackrel{\circ}{0}$ & $18^{\circ}$ & $-53^{\circ}$ & 18 & 2.8 & Var \\
\hline Puppid-Velids (301 PUP) & Dec & $01-$ Dec 15 & (Dec & $07)$ & $\left(255^{\circ}\right)$ & $123^{\circ}$ & $-45^{\circ}$ & 40 & 2.9 & 10 \\
\hline Monocerotids (019 MON) & Dec & 05-Dec 20 & Dec & 08 & $257^{\circ}$ & $100^{\circ}$ & $+08^{\circ}$ & 41 & 3.0 & 2 \\
\hline$\sigma$-Hydrids (016 HYD) & Dec & 03-Dec 15 & Dec & 11 & $260^{\circ}$ & $127^{\circ}$ & $+02^{\circ}$ & 58 & 3.0 & 3 \\
\hline Geminids (004 GEM) & Dec & 04-Dec 17 & Dec & 14 & 262.2 & $112^{\circ}$ & $+33^{\circ}$ & 35 & 2.6 & 120 \\
\hline Comae Ber. (020 COM) & Dec & 12-Dec 23 & Dec & 15 & $264^{\circ}$ & $175^{\circ}$ & $+18^{\circ}$ & 65 & 3.0 & 3 \\
\hline Dec. L. Minorids (032 DLM) & Dec & 05-Feb 04 & Dec & 19 & $268^{\circ}$ & $161^{\circ}$ & $+30^{\circ}$ & 64 & 3.0 & 5 \\
\hline Ursids (015 URS) & Dec & 17-Dec 26 & Dec & 22 & $270 \stackrel{\circ}{7}$ & $217^{\circ}$ & $+76^{\circ}$ & 33 & 3.0 & 10 \\
\hline
\end{tabular}

Table 6 (next page). Radiant positions during the year in $\alpha$ and $\delta$. 


\begin{tabular}{|c|c|c|c|c|c|c|c|c|c|c|c|c|c|c|c|}
\hline \multicolumn{2}{|c|}{ Date } & \multicolumn{2}{|c|}{ ANT } & \multicolumn{2}{|c|}{ QUA } & \multicolumn{2}{|c|}{ DLM } & & & & & & & & \\
\hline Jan & 0 & $112^{\circ}$ & $+21^{\circ}$ & $228^{\circ}$ & $+50^{\circ}$ & $172^{\circ}$ & $+25^{\circ}$ & & & & & & & & \\
\hline Jan & 5 & $117^{\circ}$ & $+20^{\circ}$ & $231^{\circ}$ & $+49^{\circ}$ & $176^{\circ}$ & $+23^{\circ}$ & & & & & & & & \\
\hline Jan & 10 & $122^{\circ}$ & $+19^{\circ}$ & $234^{\circ}$ & $+48^{\circ}$ & $180^{\circ}$ & $+21^{\circ}$ & & & & & & & & \\
\hline Jan & 15 & $127^{\circ}$ & $+17^{\circ}$ & & & $185^{\circ}$ & $+19^{\circ}$ & & & & & & & & \\
\hline Jan & 20 & $132^{\circ}$ & $+16^{\circ}$ & & & $189^{\circ}$ & $+17^{\circ}$ & & & & & & & & \\
\hline Jan & 25 & $138^{\circ}$ & $+15^{\circ}$ & & & $193^{\circ}$ & $+15^{\circ}$ & & $\mathrm{CE}$ & & & & & & \\
\hline Jan & 30 & $143^{\circ}$ & $+13^{\circ}$ & & & $198^{\circ}$ & $+12^{\circ}$ & $200^{\circ}$ & $-57^{\circ}$ & & & & & & \\
\hline Feb & 5 & $149^{\circ}$ & $+11^{\circ}$ & & & $203^{\circ}$ & $+10^{\circ}$ & $208^{\circ}$ & $-59^{\circ}$ & & & & & & \\
\hline Feb & 10 & $154^{\circ}$ & $+9^{\circ}$ & & & & & $214^{\circ}$ & $-60^{\circ}$ & & & & & & \\
\hline Feb & 15 & $159^{\circ}$ & $+7^{\circ}$ & & & & & $220^{\circ}$ & $-62^{\circ}$ & & & & & & \\
\hline Feb & 20 & $164^{\circ}$ & $+5^{\circ}$ & \multicolumn{2}{|c|}{ GNO } & & & $225^{\circ}$ & $-63^{\circ}$ & & & & & & \\
\hline Feb & 28 & $172^{\circ}$ & $+2^{\circ}$ & $225^{\circ}$ & $-51^{\circ}$ & & & & & & & & & & \\
\hline Mar & 5 & $177^{\circ}$ & $0^{\circ}$ & $230^{\circ}$ & $-50^{\circ}$ & & & & & & & & & & \\
\hline Mar & 10 & $182^{\circ}$ & $-2^{\circ}$ & $235^{\circ}$ & $-50^{\circ}$ & & & & & & & & & & \\
\hline Mar & 15 & $187^{\circ}$ & $-4^{\circ}$ & $240^{\circ}$ & $-50^{\circ}$ & & & & & & & & & & \\
\hline Mar & 20 & $192^{\circ}$ & $-6^{\circ}$ & $245^{\circ}$ & $-49^{\circ}$ & & & & & & & & & & \\
\hline Mar & 25 & $197^{\circ}$ & $-7^{\circ}$ & $250^{\circ}$ & $-49^{\circ}$ & & & & & & & & & & \\
\hline Mar & 30 & $202^{\circ}$ & $-9^{\circ}$ & $255^{\circ}$ & $-49^{\circ}$ & & & & & & & & & & \\
\hline Apr & 5 & $208^{\circ}$ & $-11^{\circ}$ & & & & & & & & & & & & \\
\hline Apr & 10 & $213^{\circ}$ & $-13^{\circ}$ & & $\mathbf{R}$ & & PU & & & & & & & & \\
\hline Apr & 15 & $218^{\circ}$ & $-15^{\circ}$ & $263^{\circ}$ & $+34^{\circ}$ & $106^{\circ}$ & $-44^{\circ}$ & & $\Gamma A$ & & & & & & \\
\hline Apr & 20 & $222^{\circ}$ & $-16^{\circ}$ & $269^{\circ}$ & $+34^{\circ}$ & $109^{\circ}$ & $-45^{\circ}$ & $323^{\circ}$ & $-7^{\circ}$ & & & & & & \\
\hline Apr & 25 & $227^{\circ}$ & $-18^{\circ}$ & $274^{\circ}$ & $+34^{\circ}$ & $111^{\circ}$ & $-45^{\circ}$ & $328^{\circ}$ & $-5^{\circ}$ & & & & & & \\
\hline Apr & 30 & $232^{\circ}$ & $-19^{\circ}$ & & & & & $332^{\circ}$ & $-3^{\circ}$ & & LY & & & & \\
\hline May & 05 & $237^{\circ}$ & $-20^{\circ}$ & & & & & $337^{\circ}$ & $-1^{\circ}$ & $283^{\circ}$ & $+44^{\circ}$ & & & & \\
\hline May & 10 & $242^{\circ}$ & $-21^{\circ}$ & & & & & $341^{\circ}$ & $+1^{\circ}$ & $288^{\circ}$ & $+44^{\circ}$ & & & & \\
\hline May & 15 & $247^{\circ}$ & $-22^{\circ}$ & & & & & $345^{\circ}$ & $+3^{\circ}$ & $293^{\circ}$ & $+45^{\circ}$ & & & & \\
\hline May & 20 & $252^{\circ}$ & $-22^{\circ}$ & & & & & $349^{\circ}$ & $+5^{\circ}$ & & & & & & \\
\hline May & 25 & $256^{\circ}$ & $-23^{\circ}$ & & & & & $353^{\circ}$ & $+7^{\circ}$ & & & & & & \\
\hline May & 30 & $262^{\circ}$ & $-23^{\circ}$ & & RI & & & & & & & & & & \\
\hline Jun & 5 & $267^{\circ}$ & $-23^{\circ}$ & $42^{\circ}$ & $+24^{\circ}$ & & & & & & & & & & \\
\hline Jun & 10 & $272^{\circ}$ & $-23^{\circ}$ & $47^{\circ}$ & $+24^{\circ}$ & & & & & & & & & & \\
\hline Jun & 15 & $276^{\circ}$ & $-23^{\circ}$ & & & & & & & & & & & & \\
\hline Jun & 20 & $281^{\circ}$ & $-23^{\circ}$ & & 30 & & & & & & & & & & \\
\hline Jun & 25 & $286^{\circ}$ & $-22^{\circ}$ & $223^{\circ}$ & $+48^{\circ}$ & & & & & & & & & & \\
\hline Jun & 30 & $291^{\circ}$ & $-21^{\circ}$ & $225^{\circ}$ & $+47^{\circ}$ & & AP & & & & & & & & \\
\hline Jul & 5 & $296^{\circ}$ & $-20^{\circ}$ & & & $285^{\circ}$ & $-16^{\circ}$ & & & & & & & & \\
\hline Jul & 10 & $300^{\circ}$ & $-19^{\circ}$ & & IR & $289^{\circ}$ & $-15^{\circ}$ & $325^{\circ}$ & $-19^{\circ}$ & & $\mathbf{A U}$ & & & & \\
\hline Jul & 15 & $305^{\circ}$ & $-18^{\circ}$ & $6^{\circ}$ & $+50^{\circ}$ & $294^{\circ}$ & $-14^{\circ}$ & $329^{\circ}$ & $-19^{\circ}$ & $330^{\circ}$ & -34 & & & & \\
\hline Jul & 20 & $310^{\circ}$ & $-17^{\circ}$ & $11^{\circ}$ & $+52^{\circ}$ & $299^{\circ}$ & $-12^{\circ}$ & $333^{\circ}$ & $-18^{\circ}$ & $334^{\circ}$ & -33 & & & & \\
\hline Jul & 25 & $315^{\circ}$ & $-15^{\circ}$ & $22^{\circ}$ & $+53^{\circ}$ & $303^{\circ}$ & $-11^{\circ}$ & $337^{\circ}$ & $-17^{\circ}$ & $338^{\circ}$ & -31 & & & & \\
\hline Jul & 30 & $319^{\circ}$ & $-14^{\circ}$ & $29^{\circ}$ & $+54^{\circ}$ & $307^{\circ}$ & $-10^{\circ}$ & $340^{\circ}$ & $-16^{\circ}$ & $343^{\circ}$ & -29 & & $\mathrm{CG}$ & & \\
\hline Aug & 5 & $325^{\circ}$ & $-12^{\circ}$ & $37^{\circ}$ & $+56^{\circ}$ & $313^{\circ}$ & $-8^{\circ}$ & $345^{\circ}$ & $-14^{\circ}$ & $348^{\circ}$ & -27 & $283^{\circ}$ & $+58^{\circ}$ & & \\
\hline Aug & 10 & $330^{\circ}$ & $-10^{\circ}$ & $45^{\circ}$ & $+57^{\circ}$ & $318^{\circ}$ & $-6^{\circ}$ & $349^{\circ}$ & $-13^{\circ}$ & $352^{\circ}$ & -26 & $284^{\circ}$ & $+58^{\circ}$ & & \\
\hline Aug & 15 & $335^{\circ}$ & $-8^{\circ}$ & $51^{\circ}$ & $+58^{\circ}$ & & & $352^{\circ}$ & $-12^{\circ}$ & & & $285^{\circ}$ & $+59^{\circ}$ & & \\
\hline Aug & 20 & $340^{\circ}$ & $-7^{\circ}$ & $57^{\circ}$ & $+58^{\circ}$ & & JR & $356^{\circ}$ & $-11^{\circ}$ & & & $286^{\circ}$ & $+59^{\circ}$ & & \\
\hline Aug & 25 & $344^{\circ}$ & $-5^{\circ}$ & $63^{\circ}$ & $+58^{\circ}$ & $85^{\circ}$ & $+40^{\circ}$ & & & & & $288^{\circ}$ & $+60^{\circ}$ & & \\
\hline Aug & 30 & $349^{\circ}$ & $-3^{\circ}$ & & & $90^{\circ}$ & $+39^{\circ}$ & & E & & & $289^{\circ}$ & $+60^{\circ}$ & & \\
\hline Sep & 5 & $355^{\circ}$ & $-1^{\circ}$ & & ГА & $96^{\circ}$ & $+39^{\circ}$ & $43^{\circ}$ & $+40^{\circ}$ & & & & & & \\
\hline Sep & 10 & $0^{\circ}$ & $+1^{\circ}$ & $12^{\circ}$ & $+3^{\circ}$ & $102^{\circ}$ & $+39^{\circ}$ & $48^{\circ}$ & $+40^{\circ}$ & & & & & & \\
\hline Sep & 15 & & & $15^{\circ}$ & $+4^{\circ}$ & & & $53^{\circ}$ & $+40^{\circ}$ & & & & & & \\
\hline Sep & 20 & & & $18^{\circ}$ & $+5^{\circ}$ & & $5 X$ & $59^{\circ}$ & $+41^{\circ}$ & & & & & & \\
\hline Sep & 25 & & & $21^{\circ}$ & $+6^{\circ}$ & $150^{\circ}$ & $0^{\circ}$ & & & & & & & & \\
\hline Sep & 30 & & & $25^{\circ}$ & $+7^{\circ}$ & $155^{\circ}$ & $0^{\circ}$ & & RI & & & & $\mathrm{CT}$ & & \\
\hline Oct & 5 & & & $28^{\circ}$ & $+8^{\circ}$ & & & $85^{\circ}$ & $+14^{\circ}$ & & $\mathbf{A U}$ & $165^{\circ}$ & $+78^{\circ}$ & & RA \\
\hline Oct & 10 & & & $32^{\circ}$ & $+9^{\circ}$ & & & $88^{\circ}$ & $+15^{\circ}$ & $82^{\circ}$ & $+45^{\circ}$ & & & $262^{\circ}$ & $+54^{\circ}$ \\
\hline Oct & 15 & $99^{\circ}$ & $+27^{\circ}$ & $36^{\circ}$ & $+11^{\circ}$ & & ГА & $91^{\circ}$ & $+15^{\circ}$ & $87^{\circ}$ & $+43^{\circ}$ & & MI & & \\
\hline Oct & 20 & $104^{\circ}$ & $+27^{\circ}$ & $40^{\circ}$ & $+12^{\circ}$ & $38^{\circ}$ & $+18^{\circ}$ & $94^{\circ}$ & $+16^{\circ}$ & $92^{\circ}$ & $+41^{\circ}$ & $158^{\circ}$ & $+39^{\circ}$ & & \\
\hline Oct & 25 & $109^{\circ}$ & $+27^{\circ}$ & $43^{\circ}$ & $+13^{\circ}$ & $43^{\circ}$ & $+19^{\circ}$ & $98^{\circ}$ & $+16^{\circ}$ & & & $163^{\circ}$ & $+37^{\circ}$ & & \\
\hline Oct & 30 & & & $47^{\circ}$ & $+14^{\circ}$ & $47^{\circ}$ & $+20^{\circ}$ & $101^{\circ}$ & $+16^{\circ}$ & & & $168^{\circ}$ & $+35^{\circ}$ & & \\
\hline Nov & 5 & & & $52^{\circ}$ & $+15^{\circ}$ & $52^{\circ}$ & $+21^{\circ}$ & $105^{\circ}$ & $+17^{\circ}$ & & $\mathrm{OO}$ & & & & \\
\hline Nov & 10 & & & $56^{\circ}$ & $+15^{\circ}$ & $56^{\circ}$ & $+22^{\circ}$ & & & $147^{\circ}$ & $+24^{\circ}$ & & & & MO \\
\hline Nov & 15 & $81^{\circ}$ & $+16^{\circ}$ & $60^{\circ}$ & $+16^{\circ}$ & $61^{\circ}$ & $+23^{\circ}$ & & & $150^{\circ}$ & $+23^{\circ}$ & & & $112^{\circ}$ & $+2^{\circ}$ \\
\hline Nov & 20 & $84^{\circ}$ & $+16^{\circ}$ & $64^{\circ}$ & $+16^{\circ}$ & $65^{\circ}$ & $+24^{\circ}$ & & & $153^{\circ}$ & $+21^{\circ}$ & & & $116^{\circ}$ & $+1^{\circ}$ \\
\hline Nov & 25 & $88^{\circ}$ & $+16^{\circ}$ & & & $70^{\circ}$ & $+24^{\circ}$ & & HO & $156^{\circ}$ & $+20^{\circ}$ & & UP & $120^{\circ}$ & $0^{\circ}$ \\
\hline Nov & 30 & $92^{\circ}$ & $+16^{\circ}$ & & M & $74^{\circ}$ & $+24^{\circ}$ & $14^{\circ}$ & $-52^{\circ}$ & $159^{\circ}$ & $+19^{\circ}$ & $120^{\circ}$ & $-45^{\circ}$ & $91^{\circ}$ & $+8^{\circ}$ \\
\hline Dec & 5 & $85^{\circ}$ & $+23^{\circ}$ & $103^{\circ}$ & $+33^{\circ}$ & $149^{\circ}$ & $+37^{\circ}$ & $18^{\circ}$ & $-53^{\circ}$ & $122^{\circ}$ & $+3^{\circ}$ & $122^{\circ}$ & $-45^{\circ}$ & $98^{\circ}$ & $+9^{\circ}$ \\
\hline Dec & 10 & $90^{\circ}$ & $+23^{\circ}$ & $108^{\circ}$ & $+33^{\circ}$ & $153^{\circ}$ & $+35^{\circ}$ & $22^{\circ}$ & $-53^{\circ}$ & $126^{\circ}$ & $+2^{\circ}$ & $125^{\circ}$ & $-45^{\circ}$ & $101^{\circ}$ & $+8^{\circ}$ \\
\hline Dec & 15 & $96^{\circ}$ & $+23^{\circ}$ & $113^{\circ}$ & $+33^{\circ}$ & $157^{\circ}$ & $+33^{\circ}$ & $174^{\circ}$ & $+19^{\circ}$ & $130^{\circ}$ & $+1^{\circ}$ & $128^{\circ}$ & $-45^{\circ}$ & $105^{\circ}$ & $+7^{\circ}$ \\
\hline Dec & 20 & $101^{\circ}$ & $+23^{\circ}$ & $118^{\circ}$ & $+32^{\circ}$ & $161^{\circ}$ & $+31^{\circ}$ & $177^{\circ}$ & $+18^{\circ}$ & & YD & $217^{\circ}$ & $+76^{\circ}$ & $108^{\circ}$ & $+7^{\circ}$ \\
\hline Dec & 25 & $106^{\circ}$ & $+22^{\circ}$ & & JA & $166^{\circ}$ & $+28^{\circ}$ & $180^{\circ}$ & $+16^{\circ}$ & & & $217^{\circ}$ & $+74^{\circ}$ & & $\mathrm{ON}$ \\
\hline Dec & 30 & ${ }^{111^{\circ}} \mathbf{A}$ & $\begin{array}{l}+21^{\circ} \\
\text { ST }\end{array}$ & $226^{\circ}$ & $+50^{\circ}$ & $\begin{array}{r}170^{\circ} \\
\mathrm{D}\end{array}$ & $\begin{array}{l}+26^{\circ} \\
\mathrm{M}\end{array}$ & & $\mathrm{M}$ & & & & $\mathbf{R S}$ & & \\
\hline
\end{tabular}


Table 7. Working List of Daytime Radio Meteor Showers. According to the naming rules, the shower names should all have 'Daytime' added (it is omitted in this Table). An asterisk ('*') in the 'Max date' column indicates that source may have additional peak times, as noted in the text above. See also the details given for the Arietids (171 ARI) and the Sextantids (221 DSX) in the text part of the Calendar. Rates are expected to be low (L), medium (M) or high (H). An asterisk in the 'Rate' column shows the suggested rate may not recur in all years. (Thanks to Jean-Louis Rault and Cis Verbeeck for comments on the Table.)

\begin{tabular}{|c|c|c|c|c|c|c|}
\hline \multirow[t]{2}{*}{ Shower } & \multirow[t]{2}{*}{ Activity } & \multirow{2}{*}{$\begin{array}{l}\text { Max } \\
\text { Date }\end{array}$} & \multirow{2}{*}{$\begin{array}{l}\lambda_{\odot} \\
2000\end{array}$} & \multicolumn{2}{|c|}{ Radiant } & \multirow[t]{2}{*}{ Rate } \\
\hline & & & & $\alpha$ & $\delta$ & \\
\hline Capricornids/Sagittariids (115 DCS) & Jan $13-$ Feb 04 & Feb $01^{*}$ & 312.5 & $299^{\circ}$ & $-15^{\circ}$ & $\mathrm{M}^{*}$ \\
\hline$\chi$-Capricornids (114 DXC) & Jan 29-Feb 28 & Feb $13^{*}$ & 324.7 & $315^{\circ}$ & $-24^{\circ}$ & $\mathrm{L}^{*}$ \\
\hline April Piscids (144 APS) & Apr 20-Apr 26 & Apr 22 & 32.5 & $9^{\circ}$ & $+11^{\circ}$ & $\mathrm{L}$ \\
\hline$\varepsilon$-Arietids (154 DEA) & Apr 24-May 27 & May 09 & 48.7 & $44^{\circ}$ & $+21^{\circ}$ & $\mathrm{L}$ \\
\hline May Arietids (294 DMA) & May 04-Jun 06 & May 16 & 55.5 & $37^{\circ}$ & $+18^{\circ}$ & $\mathrm{L}$ \\
\hline$o$-Cetids（293 DCE） & May 05-Jun 02 & May 20 & 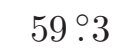 & $28^{\circ}$ & $-04^{\circ}$ & $M^{*}$ \\
\hline Arietids (171 ARI) & May 14-Jun 24 & Jun 07 & 76.5 & $42^{\circ}$ & $+25^{\circ}$ & $\mathrm{H}$ \\
\hline$\zeta$-Perseids (172 ZPE) & May 20-Jul 05 & Jun $09^{*}$ & 78.6 & $62^{\circ}$ & $+23^{\circ}$ & $\mathrm{H}$ \\
\hline$\beta$-Taurids (173 BTA) & Jun 05-Jul 17 & Jun 28 & 96.7 & $86^{\circ}$ & $+19^{\circ}$ & M \\
\hline$\gamma$-Leonids (203 GLE) & Aug 14-Sep 12 & Aug 25 & 152.2 & $155^{\circ}$ & $+20^{\circ}$ & $\mathrm{L}^{*}$ \\
\hline Sextantids (221 DSX) & Sep 09-Oct 09 & Sep $27^{*}$ & 184.3 & $152^{\circ}$ & $0^{\circ}$ & $M^{*}$ \\
\hline
\end{tabular}




\section{Useful addresses}

A new feature on the IMO's website, introduced in 2015, is the online fireball form, which allows the submission of data on bright meteors. It also allows access to a database of fireball events, including graphical overviews showing observer locations, with details from witness' reports. This can be found here: http://fireballs.imo.net/members/imo/report

For more information on observing techniques, to see the latest results from well-observed major meteor showers and unusual shower outbursts, or when you wish to submit your results, please use the IMO's website, www. imo.net as your first stop. Questions can be mailed to the appropriate address (note the word "meteor" must feature in your message's "subject" line to pass the anti-spam filters):

For especially bright meteors: fireball@imo.net

For meteor still imaging: photo@imo.net

For forward-scatter radio observing: radio@imo.net

For meteor moving-imaging: video@imo.net

For visual observing: visual@imo.net

The IMO has Commssions for various fields, about which you may enquire with the respective director:

Photographic Commission: William Ward, School of Engineering, Rankine Building, Oakfield Avenue, Glasgow G12 8LT, Scotland, U.K.; e-mail: William.Ward@glasgow.ac.uk

Radio Commission: Jean-Louis Rault, Société Astronomique de France, 16 Rue de la Valleé, 91360 Epinay sur Orge, France; e-mail: f6agr@orange.fr

Video Commission Sirko Molau, Abenstalstraße 13b, D-84072 Seysdorf, Germany; e-mail: sirko@molau.de

Visual Commission: Rainer Arlt, Bahnstraße 11, D-14974 Ludwigsfelde, Germany; e-mail: rarlt@aip.de

For IMO membership applications, please contact the Secretary-General lunro . imo . usa@cox . net. Those unable to access the Internet may write for information to Robert Lunsford, IMO SecretaryGeneral, 1828 Cobblecreek Street, Chula Vista, CA 91913-3917, USA.

When using ordinary mail, please try to enclose return postage, either in the form of stamps (same country only) or as an International Reply Coupon (I.R.C. - available from main postal outlets). Thank you!

(c) International Meteor Organization, 2015. 